Hydrol. Earth Syst. Sci., 17, 3039-3057, 2013

www.hydrol-earth-syst-sci.net/17/3039/2013/

doi:10.5194/hess-17-3039-2013

(c) Author(s) 2013. CC Attribution 3.0 License.

\title{
Sedimentation monitoring including uncertainty analysis in complex floodplains: a case study in the Mekong Delta
}

\author{
N. V. Manh, B. Merz, and H. Apel \\ GFZ - German Research Center for Geoscience, Section 5.4 Hydrology, Potsdam, Germany \\ Correspondence to: N. V. Manh (manh@gfz-potsdam.de) \\ Received: 11 December 2012 - Published in Hydrol. Earth Syst. Sci. Discuss.: 11 January 2013 \\ Revised: 16 June 2013 - Accepted: 24 June 2013 - Published: 1 August 2013
}

\begin{abstract}
Quantity and quality of sediment deposition in complex floodplains are affected by many processes that are typically highly spatially and temporally variable and hard to quantify exactly. The main processes in this context are suspended sediment transport dynamics in rivers, floodplain channel interactions, and internal floodplain processes. In consequence, any point measurement of sedimentation in floodplains contains a high degree of uncertainty, both stemming from measurement errors and from the lack of representativeness for a larger area. However, up to now, uncertainty analyses have not been performed as part of publications on floodplain sedimentation data. Therefore the present work illustrates a field sampling strategy aiming at the monitoring of floodplain deposition and spatial variability on a large scale and at the quantification of uncertainties associated to sediment deposition data. The study was performed in the Mekong Delta, being an example for a large and complex floodplain with a high degree of anthropogenic disturbances. We present a procedure for the quantification of the uncertainty associated to the data, based on the design of the monitoring campaign, sampling procedures, and floodplain characteristics. Sediment traps were distributed strategically over the floodplain in clusters of three mat traps representing one monitoring point. The uncertainty originating from collection of the traps from still ponding water is quantified by lab experiments. The overall uncertainty of the deposition samples and the associated nutrient content is quantified in a Monte Carlo simulation and illustrated by uncertainty bounds. For the study area the results show a very high variability of the annual floodplain deposition $\left(2.2-60 \mathrm{~kg} \mathrm{~m}^{-2}\right)$ with uncertainty bounds ranging from -61 to $+129 \%$ relative to overall mean deposition of $11.4 \mathrm{~kg} \mathrm{~m}^{-2}$. No correlations in the spatial distribution of sedimentation in the
\end{abstract}

floodplains could be found. This is caused by the highly complex channel and dike system and the high number of hydraulic structures. Also, no differences in deposition between floodplain compartments protected with high and low dikes could be detected. However, it can be shown that within single floodplain compartments the spatial deposition variability depends on the dike levels and operation and location of hydraulic structures.

\section{Introduction}

Sediment deposition in floodplains of river deltas is controlled by sediment delivery from the upstream catchment, but also by characteristics of the particular delta. The delivery from the catchment, i.e., the suspended sediment transport, is controlled by climate, geography, soil types, land cover, and dam construction and operation. For the Mekong the impact of reservoir construction and operation in the Chinese part (Lancang) has been studied by Lu and Siew (2006), Fu and He (2007), Fu et al. (2008), Kummu and Varis (2007), Kummu et al. (2010), Walling (2008), Gupta et al. (2012), Liu and He (2012), and Liu et al. (2013) all showing that the dams reduced the sediment delivery from the Lancang after closure of the dams. The spatial variability of floodplain sedimentation is typically very high, due to the variability of the factors influencing supplied sediment and the actual deposition and erosion in the delta. In addition to the natural variability both sediment supply from the upstream catchment as well as the deposition in the delta show a high degree of anthropogenic influence in many regions of the world (e.g., Ericson et al., 2006; Syvitsky and Saito, 2007; Syvitsky et al., 2009; Syvitsky and Higgins, 2012). 
In the Vietnamese part of the Mekong Delta (VMD), this interference is extraordinarily high. The VMD is known as the "rice bowl" of Southeast Asia. Almost the complete delta is used for agricultural production and dissected by a dense channel network partitioning of the floodplains into compartments. The compartments are enclosed by dikes for crop (low dikes) and flood (high dikes) protection. The question of increasing the number and length of the flood protection (high dikes) is under debate, because it enables cropping of a third crop per year during the flood period by blocking the floodplain inundation completely. This reduces the input of sediment and thus natural fertilizers, requiring a higher input of artificial mineral fertilizers and other agro-chemicals. However, the importance of natural floodplain sedimentation for agriculture, but also for the fishing industry and the ecosystem has been stressed by the Mekong River Commission (MRC, 2010). In addition to these ecological and economical facets, floodplain sedimentation is also vital for counterbalancing deltaic subsidence. The subsidence is caused by natural compaction, but also anthropogenic causes as overexploitation of ground water and urbanization (Syvitski et al., 2009; Syvitsky and Higgins, 2012; Wang et al., 2011). These facts underline the importance of a good understanding and quantification of floodplain sedimentation.

Almost all of the floodplains in the MD are compartmented by dike rings, and in case of high level dike rings the floodplain inundation is typically controlled by operation of sluice gates and pumps (Hung et al., 2012). This interplay of different controlling factors suggests a high spatial variability of floodplain sedimentation (Hung et al., 2013a). This expected spatial variability constricts the value of single point measurements. Considering also the known errors in sediment deposition measurements, it becomes clear that (a) a representative monitoring of floodplain sedimentation for a large delta is a difficult task in general, and (b) there is a clear need for a thorough estimation of the uncertainties of sedimentation data. The latter aspect facilitates a proper use and interpretation of the data and improves the credibility of the derived results and recommendations. The uncertainty analysis should identify the possible epistemic ("lack of knowledge") and aleatory (natural variability) uncertainty sources and try to quantify them.

A number of studies monitoring sedimentation on floodplains have been published, often using mat traps to quantify the accumulative sediment deposition during flood events (Asselmann and Middelkoop, 1995; Steiger et al., 2001, 2003; Middelkoop, 2005; Büttner et al., 2006; Baborowksi et al., 2007; Hung et al., 2013b). But to the knowledge of the authors, these used multiple traps to quantify the deposition at a single point (Asselmann and Middelkoop, 1995; Steiger et al., 2001; Middelkoop, 2005; Baborowksi et al., 2007). However, none of the studies quantified the uncertainties, neither epistemic sampling uncertainty, nor aleatory uncertainty related to spatial variability. There are publications on uncertainty analysis in sediment research (Salas and Shin,
1999; Navratil et al., 2011; Shamsudin et al., 2012). However, these studies focus on other aspects such as reservoir sedimentation, urban retention pond or suspended sediment mobilization and transport in small mountainous catchments.

This study presents a monitoring scheme aiming at the quantification of spatial variability of sediment and associated nutrient floodplain deposition in the MD, as well as a strategy to quantify the uncertainty of the sediment sampling scheme. The study is the first large-scale monitoring of floodplain sedimentation in the MD. In addition, it also provides uncertainty estimates for the monitoring results for the first time, thus indicating the trustworthiness of sediment trap data. The uncertainty analysis procedure is adopted from the procedures developed by Apel et al. (2004, 2006, 2008) in the context of flood risk assessment. The derived data can contribute to the debate on the economic value of floodplain deposition in terms of nutrients, which is a hot topic in the MD. There is a trend to totally blocking floodplain inundation in favor of three cropping periods per year that have to be sustained by the increasing input of mineral fertilizers (Ve, 2009). In addition, the results can also serve as a quantitative basis for the discussion of the importance of floodplain deposition to counterbalance the subsidence of the delta.

\section{Study area and site selection}

The Mekong Delta begins near Phnom Penh in Cambodia where the largest tributary, the Bassac River, branches away from the Mekong River. Both branches formed the huge fertile flat plain in southern Vietnam, the Vietnamese part of the VMD. It is known as the most complex channel network in the world and it is the habitat of more than 10 million people. The annual inundated floodplain area in the Mekong Delta within the Vietnamese territory is around $19500 \mathrm{~km}^{2}$ (Hung et al., 2012) with a channel network of $91000 \mathrm{~km}$ in length (MARD, 2012) (Fig. 1).

The annual flood lasts from July or August to the end of November or mid-December. The main inundated areas are located in the northern part of the VMD, which are differentiated into the Plan of Reeds east of the Mekong (Tien in Vietnamese) branch, the Long Xuyen Quadrangle west of the Bassac (Hau in Vietnamese) branch, and the area between the Tien and Hau rivers. A number of secondary channels connected to either the Tien or Hau River facilitate widespread distribution of the flood water to the floodplains.

Deposited sediments play a very important role for the agricultural development in the MD. The annual suspended sediment load into the MD is about 160 million tons based on Walling (2008), and 110-150 million tons based on Milliman and Farnsworth (2011). In addition, Milliman and Farnsworth (2011) provided the number of 60 million tons of total dissolved solids per year. Approximately $80 \%$ of Mekong delivered sediment is trapped within the delta area (Xue et al., 2010). The annual loads of total nitrogen (TN) 


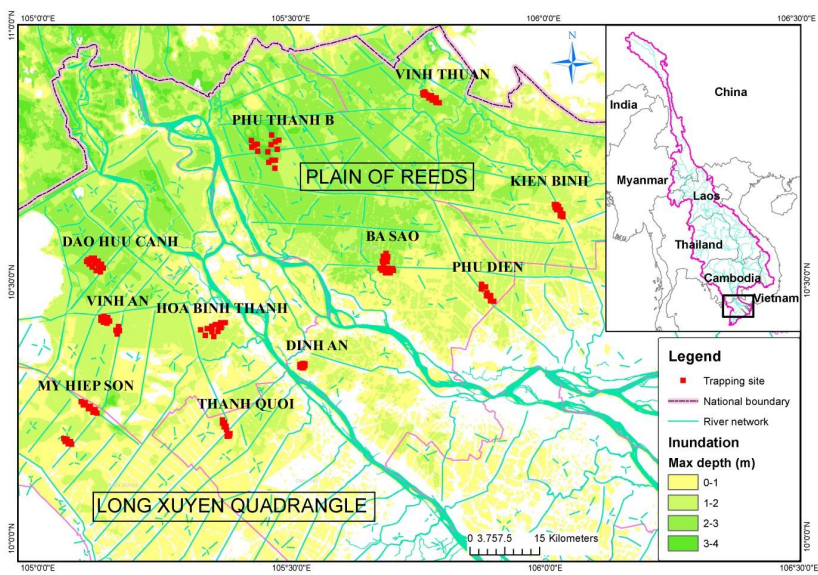

Fig. 1. The study area in the MD in Vietnam: the main map shows the mean of maximum observed inundation depths over the 2000-2010 period, and the 11 selected sites including 19 compartments of either high dike or low dike systems. The map (top right panel) shows the entire Mekong River basin with the Mekong Delta marked by a gray box.

and total phosphorous (TP) at the river mouths of the MD were estimated to be $2.7 \times 10^{4} \mathrm{tN} \mathrm{yr}^{-1}$ and $9 \times 10^{3} \mathrm{tP} \mathrm{yr}^{-1}$ (1987-1999) (Yoshimura et al., 2009).

Flood control is a hot issue in the VMD, low dike protection vs. high dike protection is under intense debate. However quantitative studies about floodplain sedimentation and associated nutrient deposition do not exist. Thus also an estimation of the economic benefits of the floodplain inundation and natural fertilizer input by sediments vs. higher flood protection and control is missing at present. In general terms, assumed higher suspended sediments and sedimentation on floodplains with low dikes does not only supply more natural fertilizer for agriculture, but also increase the output of wild catch fishery on floodplains over the flood season. On the other side, a high dike system enables growing a third rice crop per year, but requires more artificial mineral fertilizers.

The agricultural system is adapted to the annual floods. Traditionally, two crops are grown around the flood period utilizing the sediments and flood waters for irrigation and as nutrient source. Recently, a third crop was introduced in the shallow inundated areas of the delta, where the flood protection systems are well developed and floodplain inundation can be controlled completely under normal flood conditions. The spatial extent of the three crop system depends on the flood magnitude and economic factors. The present study aims to provide a first quantitative database for the estimation of the economic benefit the natural fertilizer input via flood sediments. This may serve as a basis for a cost-benefit analysis for the construction of high dike systems of triple crops area.

The study area is the entire regularly inundated floodplain in the VMD. The inundated floodplains vary year by year depending on the flood magnitude and the seasonal cropping pattern in the floodplains. These are controlled by the hydraulic structures, whose operation is based on communal agreements. The main difference of flood characteristics in the MD to other parts of the world is that the flood event is always longer than 3 months, setting it apart not only in the spatial, but also the temporal inundation extent compared to typical inundation durations from a few days to two weeks in smaller basins. Normally, the inundation duration extends from 4 to 5 months with single or double peak hydrographs. The sedimentation rate in floodplains generally depends on the following factors: (1) flood magnitude and duration; (2) distance to main rivers and associated suspended sediment concentration; (3) floodplain topography; (4) tidal regimes; (5) dikes, hydraulic structures and their operation and (6) human activities (fishing, etc.).

The floodplains in the VMD are intensively used, even during floods. Typically a portion of the flood water is retained in the floodplain compartments and used for paddy cultivation. Depending on the flood magnitude and duration and the dike elevations, the farmers start to pump the water from the floodplains at some point in December in order to enable the growth of two crops between flood seasons (Hung et al., 2012). In most cases paddy rice is grown after the flood period, thus the farmers retain ponding water on the floodplains in the range of $20-40 \mathrm{~cm}$.

During the inundation the floodplains are used for fishing, which is traditionally done with nets. This disturbs the deposition and erosion processes, but has also impacts on the sediment monitoring as it puts the sediment traps at risk of being destroyed. This adds additional uncertainty to the monitored sediment deposition, both by loss of traps as well as by resuspension and relocation processes. Thus the sediment trapping and uncertainty analysis require appropriate trap design, trap installation, trap collection, and methods to quantify the uncertainties stemming from these processes.

The selected sampling sites must be representative for the different inundation regions, inundation depths and flood protection levels. The criteria for site selections sorted by descending priority are as follows.

1. The selected sites have to be distributed on the main floodplains in the MD, including the Plan of Reeds, Long Xuyen Quadrangle and the area between Tien River and Hau River.

2. The selection is based on the flood depths at "high stage" in floodplains (Hung et al., 2012): greater than $2 \mathrm{~m}$ depth, from $1 \mathrm{~m}$ to $2 \mathrm{~m}$ depth and below $1 \mathrm{~m}$ depth. The flood depths can be determined by the intersection of inundation maps of different years derived from radar satellite images (Dung et al., 2011) and the digital elevation model (SRTM).

3. The sites should encompass full flood control compartments (termed "high dike" in Vietnam), as well 
Table 1. Sediment trap installation and collection in 19 compartments, and distance from the sites to main rivers.

\begin{tabular}{llrrrr}
\hline No & Compartment & $\begin{array}{r}\text { Number of } \\
\text { collected traps }\end{array}$ & $\begin{array}{r}\text { Number of } \\
\text { installed traps }\end{array}$ & $\begin{array}{r}\text { Percent (\%) } \\
\text { Distance } \\
\text { to river }\end{array}$ \\
\hline 1 & Vinh Thuan 1 & 9 & 15 & $60 \%$ & $50 \mathrm{~km}$ \\
2 & Vinh Thuan 2 & 20 & 27 & $74 \%$ & $50 \mathrm{~km}$ \\
3 & Kien Binh 1 & 15 & 15 & $100 \%$ & $70 \mathrm{~km}$ \\
4 & Kien Binh 2 & 27 & 27 & $100 \%$ & $71 \mathrm{~km}$ \\
5 & Phu Thanh B1 & 14 & 15 & $93 \%$ & $12 \mathrm{~km}$ \\
6 & Phu Thanh B2 & 10 & 15 & $67 \%$ & $8 \mathrm{~km}$ \\
7 & Phu Thanh B3 & 4 & 15 & $27 \%$ & $10 \mathrm{~km}$ \\
8 & Ba Sao 1 & 2 & 24 & $8 \%$ & $15 \mathrm{~km}$ \\
9 & Ba Sao 2 & 1 & 30 & $3 \%$ & $15 \mathrm{~km}$ \\
10 & Phu Dien & 1 & 24 & $4 \%$ & $40 \mathrm{~km}$ \\
11 & Dinh An & 2 & 24 & $17 \%$ & $7 \mathrm{~km}$ \\
12 & Hoa Binh Thanh & 6 & 36 & $13 \%$ & $20 \mathrm{~km}$ \\
13 & Vinh An 1 & 2 & 15 & $4 \%$ & $21 \mathrm{~km}$ \\
14 & Vinh An 2 & 1 & 27 & $48 \%$ & $15 \mathrm{~km}$ \\
15 & Dao Huu Canh & 20 & 24 & $47 \%$ & $47 \mathrm{~km}$ \\
16 & My Hiep Son 1 & 17 & 33 & $52 \%$ & $40 \mathrm{~km}$ \\
17 & My Hiep Son 2 & 17 & 24 & $4 \%$ & $18 \mathrm{~km}$ \\
18 & Thanh Quoi 1 & 1 & 15 & $13 \%$ & $18 \mathrm{~km}$ \\
19 & Thanh Quoi 2 & 2 & 447 & $38 \%$ & \\
& & 171 & & & \\
\hline
\end{tabular}

as partial flood control compartment ("low dike"). For more information on the dike system see Hung et al. (2012).

4. The sites should be suitable for monitoring of a long flooding period.

Although each site should ideally include a low dike and a high dike, this criteria could not be met everywhere. High dike compartments do not exist everywhere, so that some sites contain low dike compartments only. Finally, 11 sites were selected containing 19 compartments (cf. Fig. 1, Table 1) with overall 11 low dike and 8 high dike compartments.

\section{Methodology}

\subsection{Sediment trap design}

Sedimentation is mostly monitored by sediment traps, as shown by a number of recent studies (Steiger et al., 2001, 2003; Middelkoop, 2005; Büttner et al., 2006; Baborowksi et al., 2007; Hung et al., 2013b). Sediment traps can provide cumulative samples for different physical and chemical analyses. Flexible sediment traps are an adequate method for sampling sediment deposited by flowing water in floodplains and are in recent studies preferred to flat devices with a smoother surface, because they can represent the natural ground surface more appropriately (Steiger et al., 2003). We followed this recommendation and used flexible traps built from artificial grass with a rectangular dimension of $30 \mathrm{~cm}$ by $30 \mathrm{~cm}$ and $1.5 \mathrm{~cm}$ long tufts. To be able to retrieve the traps from still ponding water with minimum sediment loss, the traps were designed with eight strings $(60 \mathrm{~cm}$ long) attached to the corners and the middle of the sides. The traps were tested to withstand upward pulling by the strings with more than $60 \mathrm{~kg} \mathrm{~m}^{-2}$ sediment load, which is well above the maximum documented deposition of $20 \mathrm{~kg} \mathrm{~m}^{-2} \mathrm{yr}^{-1}$ in the MD (Hung et al., 2013b). When the traps are pulled up by the strings, they form a bowl-shape retaining most of the sediment (Fig. 3). However, the retrieval cannot be loss free, and it has to be expected, that the higher the deposition volume, the higher is the loss, as the overflow over the sides of the bowl is likely to carry more sediment compared to small deposition volumes. The loss due to retrieval is quantified by lab experiments presented in Sect. 3.3.1.

The traps were fixed to the ground by bamboo stakes instead of steel pins, in order to avoid injuries of the farmers when they accidentally step on them in their fields.

\subsection{Sampling scheme}

Measurement of sedimentation using clusters of traps has been performed to indicate differences in sediment accumulation over short distances (Asselmann and Middelkoop, 1995), and to calculate average deposition rates (Steiger et al., 2001; Middelkoop, 2005; Baborowksi et al., 2007). In order to increase the representativeness of a single trap for the sedimentation processes due to very high variability of local hydraulic regimes in compartments (Hung et al., 2012), 
clusters of 3 traps were installed for every monitoring point in the present study. The number of 3 traps for each cluster is a compromise between overall number of samples that could be handled with the available resources (Fig. 2) and the need for getting a quantitative insight into the sampling uncertainty at each sampling point By this repeated sampling the variability at a given location can be estimated. This variability stems from the different floodplain processes, both natural and anthropogenic, influencing the deposition. The traps of each cluster were positioned in an equiangular triangle of $2 \mathrm{~m}$ side length (Fig. 2). Each cluster was marked with flags on high poles to indicate the fishing farmers the trap location.

The farmers retain ponding water on the floodplains for the second/third crop of a year after the flood, which has consequences for the sediment monitoring. First of all, the time for trap deployment and collection is limited, as there are just a few days between the crops and the inundation where the land is not used. The traps have to be placed and collected in these short time windows, otherwise the farmers will either remove the traps, or the positioning is not possible because the floodplains are already inundated. Besides this logistical obstacle, there is also the problem that the traps have to be collected with water still ponding on the fields. This obviously introduces measurement errors, which need to be taken into account (Sect. 3.3.1). In order to quantify the spatial variability of deposition within a compartment, each compartment was equipped with several monitoring point clusters, each consisting of three traps. The monitoring points are arranged perpendicular and parallel to the expected flow direction in the compartment.

A total number of 149 trap clusters (447 traps) were deployed at the monitoring sites for the measurement campaign starting in late July 2011 and lasting until mid-December 2011. The maximum and minimum number of points (trap clusters) in a compartment were 14 and 5, respectively, while the biggest and the smallest monitored compartments are 858 hectares and 52 hectares, respectively. The distance from the sites to main rivers range from $5 \mathrm{~km}$ in the Dinh An compartment up to $71 \mathrm{~km}$ in the Kien Binh 2 compartment (Table 1). The traps were retrieved just after the flood season and before cropping activities in the fields started.

\subsection{Uncertainty analysis}

\subsubsection{Uncertainty associated to trap collection in ponding water}

Trap removal from ponding water will always produce less (or equal at best) sediment mass compared to dry trap collection. Sediments can only be lost, not gained by trap removal from ponding water, as water flowing from the trap will carry parts of the deposited sediment when the trap is pulled out of the water. In order to quantify this loss, experiments were conducted in a small reservoir, where traps

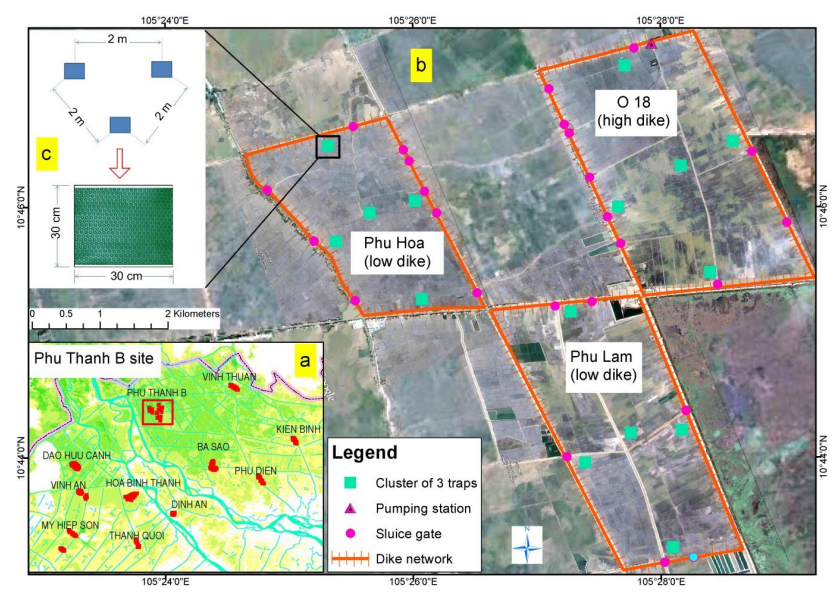

Fig. 2. Map illustrating the typical setup of the sediment traps in a site: map (a) shows all selected sites. The main map (b) describes the sediment trap installation in the study site of Phu Thanh B, map (c) shows a cluster of 3 traps, the distances between the traps and the dimension of a trap.

with known and equal dry weights are immersed. After complete mixing and following settlement of the now suspended sediment, one trap is pulled out of the water by the strings. Following the removal of one trap, the water is carefully removed from the reservoir until the remaining trap can be removed without pulling it through water. The sediment masses in the traps are determined by weighing after drying of the removed samples yielding sediment masses of wet and dry collection conditions. The tests were performed with 32 different initial sediment masses equivalent to reported annual deposition masses of $0.07 / 21 \mathrm{~kg} \mathrm{~m}^{-2} \mathrm{yr}^{-1}$, as referenced in Hung et al. (2013b). The results of this test are shown in Fig. 4, where the constraint that the wet collection mass must be lower than the dry collection is represented by the truncation line.

The regression model is $y=0.0561 x^{2}+0.6659 x+0.9141$, (1)

with constraint : $y \geq x$.

In which:

- $x$ : wet retrieval sediment mass $\left(\mathrm{kg} \mathrm{m}^{-2}\right)$,

- $y$ : dry retrieval sediment mass $\left(\mathrm{kg} \mathrm{m}^{-2}\right)$.

The $95 \%$ confidence interval (CI) of the regression, also shown in Fig. 4, shows the uncertainty stemming from the parameter estimation and is computed as $\mathrm{CI}=$ para $\pm t \sqrt{ } S$, in which para denotes the estimated parameters, $t$ depends on the confidence level, and is computed using the inverse of Student's $t$ cumulative distribution function, and $S$ is a vector of the diagonal elements from the estimated covariance matrix of the coefficient estimates (Mendenhall et al., 2009). 

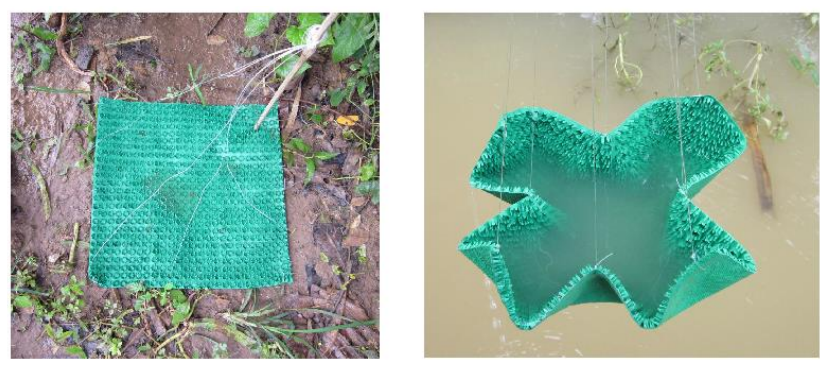

Fig. 3. The sediment trap design, strength and balance test. Left: a fixed trap on the ground, right: bowl-shape trap when pulled up.

The exponential regression models describing the data can also be justified by the trap removal procedure. When a trap is removed by pulling it upward with the strings, the mat forms a bowl-like shape. When there is only little sediment in the trap and the trap is removed carefully, only little sediment is re-suspended by the outflowing water. However, the higher deposition masses are, the closer the deposited sediment is to the brim of the "removal bowl", thus causing higher losses by the outflowing water or even direct losses in extreme cases. The uncertainty of the model is captured by confidence intervals (Apel et al., 2004). In the following this sampling uncertainty is called "wet-dry correction model". This uncertainty source represents an epistemic uncertainty source according to Merz and Thieken (2005).

\subsubsection{Deposition uncertainty}

The second uncertainty source of the sampling scheme is the deposition sampling uncertainty, i.e., the representativeness of a sediment trap measurement for the actual deposition at the sampling point. The layout in clusters of three traps aimed at the quantification of this uncertainty. For every cluster the mean and standard deviation were taken as a measure for the deposition uncertainty. In case the clusters are damaged or partially lost, a single trap had to be used to represent to deposition at the given location. In order to use these traps in the given uncertainty estimation framework instead of discarding them, we have to assume that the mean of these "single trap clusters" is represented by the measured deposition value. As this assumption is also uncertain, we "penalize" these samples with a higher degree of uncertainty (i.e., wider confidence intervals) compared to the three trap clusters. Details on this are given in Sect. "Sediment mass" below. At this point we have to emphasize that we assume normality in the distribution of the cluster trap deposition, and that the sample mean and standard deviation calculated from the trap results represent the moments of the distribution. Of course, the statistical significance of these moments is very limited due to the small sample size. However, given the constraints in practically feasible sample numbers and sample analysis, the derived statistical moments from the trap samples provide essential information for the uncertainty analysis. It has also to

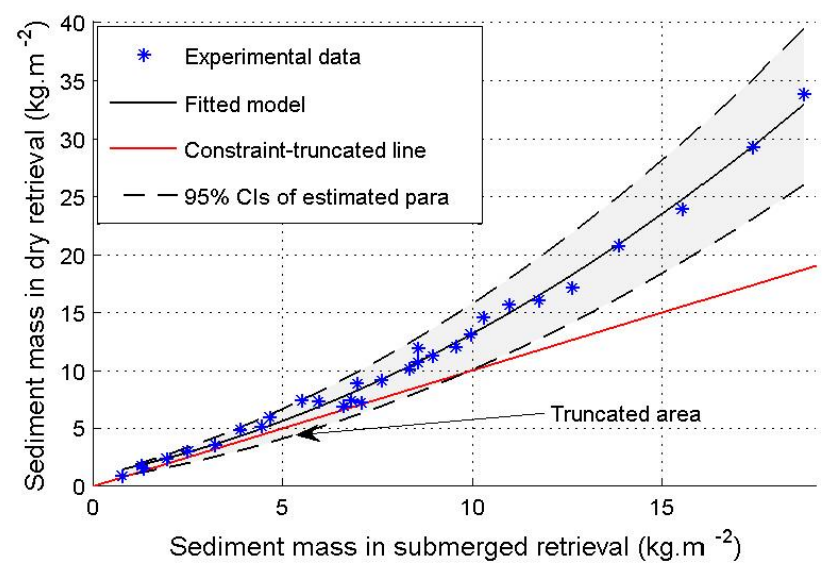

Fig. 4. Experimental results of trap retrieval from ponding water and under dry condition. The stars are the experimental data, the black solid line is the regression model, while the dashed lines indicate the $95 \%$ confidence bounds of the regression derived from the parameter uncertainty. The truncated domain is the area below the constrain line in red.

be noted that obtaining statistically significant sample sizes for the determination of the distribution of deposition masses within a trap cluster would require a much higher number of traps per cluster. This is, however, not practicable in an experimental study on this large scale. But even in a smallscale study the required number of traps per cluster (approx. $\geq 30$ ) would face the problem that the required space for this experimental setup is too large to actually depict the local deposition uncertainty, because natural spatial variability of deposition might already come into play. Thus we regard the information derived from the 3-sample clusters as an important step towards a quantification of sediment deposition uncertainty, as already this small sample size indicates a large variability. And generally speaking, we argue in line with Pappenberger and Beven (2006) that it is better to acknowledge the uncertainties in data and models, even by subjective assumptions, than to neglect the uncertainties completely and present data as deterministic and precise, while they are clearly not.

\subsubsection{Monte Carlo analysis}

The overall uncertainty stemming from the uncertainty in deposition monitoring and wet trap removal is quantified in a Monte Carlo (MC) framework. For every sampling location, the uncertainty from both sources is combined by a randomized sampling of wet deposition and subsequent wet-dry sample mass correction.

As mentioned above, we assume normality for the uncertainty distribution of the sampling uncertainty, but also for the wet-dry correction. The moments of the uncertainty distribution of the wet-dry correction model parameters are 
derived from the uncertainty bounds of the regression parameters shown in Fig. 4.

The MC uncertainty analysis was performed for deposition mass, nutrient fractions (TN, TP, TK (total potassium), TOC (total organic carbon fraction)), grain size fractions (sand, silt, clay) and $\mathrm{pH}$ (potential hydrogen). The uncertainty of the deposition mass was calculated for every monitoring point. This uncertainty was further propagated to nutrient masses by combining the deposition uncertainty with the uncertainty of the nutrient fractions. The grain size fraction and $\mathrm{pH}$ do not depend on the deposition mass, as the very small CV (coefficient of variation) values indicate, thus the spatial units of their uncertainty analysis are the compartments.

According to the different spatial units, the uncertainty analysis consists of three workflows (shown in Fig. 5): uncertainty analysis for sediment mass, nutrient fractions, and finally grain size fractions and $\mathrm{pH}$. The sediment mass workflow contains 2 branches: cluster traps (two/three traps) and single traps. Details are given below. For every parameter $5000 \mathrm{MC}$ runs were performed.

\section{Sediment mass}

The uncertainty analysis of the sediment mass is performed in 4 steps.

- Step 1: derivation of PDFs (probability density functions) for wet collected deposition mass for cluster traps and single traps

- Cluster traps: derive the PDFs based on the mean and SD (standard deviation) of each trap cluster.

- Single traps: in order to include these values in the uncertainty analysis, assumptions about the real mean and standard deviation have to be taken. First we assume that the measured value can be used as an approximation of the real cluster mean. SDs are derived from the linear correlation of the mean values to the SDs of the cluster traps. Figure 6 shows a scatter plot of the cluster means vs. the cluster standard deviations along with the linear regression and the associated 99\% confidence intervals of the linear regression. A ("mean") value from a single trap is associated with the standard deviation from the upper $99 \%$ confidence interval of the regression, thus ensuring that the missing trap values are penalized with a high degree of uncertainty. This method also considers the observed trend of decreasing $\mathrm{CV}$ with increasing deposition mass.

- Step 2: calculate the dry collection mass.

- For every trap location a wet collection mass is randomly drawn from the PDFs of step 1. From this

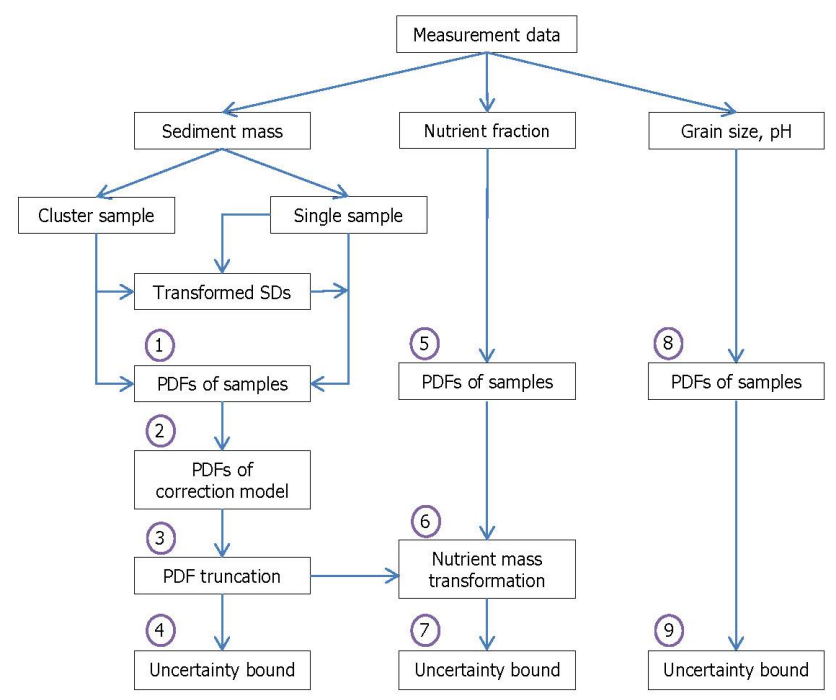

Fig. 5. Uncertainty analysis workflows for sediment mass, nutrient fractions and grain size, $\mathrm{pH}$.

wet collection mass the dry collection mass is calculated with randomly selected regression parameters. The normal PDFs of the parameters are derived from the confidence bounds of the parameters. Normality is chosen because the method providing the confidence bounds assumes normality (Student's $t$ distribution, see explanation of Eq. 2).

- Step 3: truncate the dry collection masses from step 2 by the constraint given in Eq. (3).

- Step 4: construct $95 \%$ CI of the empirical PDFs derived from the results of step 3 .

\section{Nutrient mass}

The laboratory results of nutrient analysis are expressed as a proportion of sediment mass (\%). This means that the uncertainty of nutrient mass is related to the sediment mass. Moreover, the coefficient of variation of nutrient fraction is comparatively low, as well as the correlation coefficients between sediment mass and nutrient fraction. This implies that the nutrient compounds in the sediments are approximately homogeneously distributed over the study area. Thus the uncertainty of the nutrient fractions can be calculated over a larger spatial unit as for the deposition masses. We chose to derive the overall uncertainty over the whole study area.

- Step 5: derive PDFs of nutrient fractions based on the mean and SD of nutrient fraction calculated over the whole study area. Again we assume normality in the nutrient fraction distribution. 


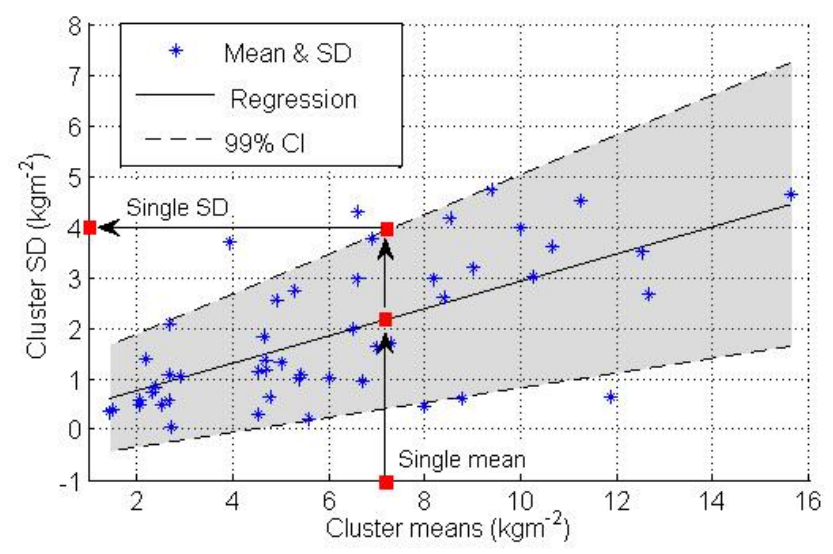

Fig. 6. Linear regression between SD and mean values derived from the multi-trap clusters.

- Step 6: create PDFs of nutrient mass by multiplying randomly selected nutrient fraction from the PDFs in step 5 with the dry collection sediment masses from step 3 .

- Step 7: construct the $95 \%$ CI for the nutrient masses from the empirical PDFs from step 6.

\section{Grain size fraction and $\mathbf{p H}$}

In order to account for the observed differences in substrate and $\mathrm{pH}$ in the $\mathrm{MD}$, the uncertainty of grain size distributions and $\mathrm{pH}$ is calculated compartment-wise. Variations in $\mathrm{pH}$ may well be caused by local redistribution of sediments. The acidic soils, e.g., in the Plain of Reeds, may influence $\mathrm{pH}$, which in turn influences the grain size distribution by flocculation. Hence, in order to capture the variability of these parameters for an appropriate spatial unit, the uncertainty is evaluated for every monitored compartment; i.e., the statistical moments are calculated from compartment aggregated sample pools. Again we assume normality of the sample distribution over the compartments.

- Step 8: derive PDFs of grain size fractions and $\mathrm{pH}$ based on means and SD over compartments.

- Step 9: construct the $95 \%$ CI from the PDFs results in step 8 for every compartment.

Finally, the results in step 4, 7, and 9 are the estimated uncertainty bounds presented as $95 \%$ confidence intervals of sediment mass for every sampling location, nutrient masses for the whole study area, and $\mathrm{pH}$ and grain size fractions for individual compartments.
Table 2. Analysis methods for physical and chemical properties of sediment samples.

\begin{tabular}{ll}
\hline Analysis & Method \\
\hline Mass & Drying and weighing in the laboratory \\
$\mathrm{D}$ & Robinson pipette method (sand $>0.063 \mathrm{~mm}>$ silt $>2 \mu$ m clay) \\
$\mathrm{pH}$ & $\mathrm{pH}$ meter: soil : water ratio, $1: 2.5$ \\
$\mathrm{TN}$ & Micro Kjeldahl: using $\mathrm{H}_{2} \mathrm{SO}_{4}-\mathrm{CuSO}_{4}$-Se, ratio: $100: 10: 1$ \\
$\mathrm{TP}$ & $\begin{array}{l}\text { Attacked by } \mathrm{H}_{2} \mathrm{SO}_{4}-\mathrm{HClO}_{4}(1: 5) \text { desalinate phosphomolybdate } \\
\text { by ascorbic acid, color comparison with photometer }\end{array}$ \\
$\mathrm{TK}$ & $\begin{array}{l}\text { Attacked by } \mathrm{HF}-\mathrm{HClO}_{4}(10: 1) \text { determine K by atomic } \\
\text { absorption }\end{array}$ \\
TOC & $\begin{array}{l}\text { Walkley-Black: oxidation by } \mathrm{H} 2 \mathrm{SO} 4-\mathrm{K} 2 \mathrm{Cr} 2 \mathrm{O} \text {, titrated } \\
\text { by FeSO }\end{array}$ \\
\hline
\end{tabular}

\section{Results and discussion}

\subsection{Monitoring results and basic descriptive statistics}

A large number of traps was lost or damaged, both due to the exceptionally high flood in this year (MRC, 2011), and fishing activities in the floodplains. The farmers owning the land where the traps were installed were informed and paid for taking care of them. However, during the flood season in the VMD the inundated land has legally no owner and everyone can fish everywhere, which partly explains the loss of some traps, as not everybody could have been informed about the monitoring activities. An overall number of 171 traps in 19 compartments could be collected, which is equivalent to $38 \%$ of all installed traps.

The number of samples used for the laboratory test is restricted due to a required minimum volume of sediments for nutrient analysis and grain size analysis, integrity of samples after transport from the fields to the laboratory for sediment mass analysis, and available budgets and laboratory capacity. Thus only 161 of 171 traps in 12 compartments could be used to measure the sediment mass. The 161 samples stem from 49 clusters of two or three traps and 26 "single trap clusters". In the "single trap clusters" the remaining two traps were lost or destroyed by the flood or farmers/fishers. The sample masses were measured after drying at room temperatures in the range of $30-35^{\circ} \mathrm{C}$ until the masses did not change over several days. This took around 6 weeks. The deposited masses are sample masses subtracted by the trap weight. The trap weights were measured prior to placement on floodplains. The weight of the traps is $180 \mathrm{~g} \pm 5 \mathrm{~g}$ based on weighing of a subset of 10 samples.

The 61 representative samples distributed over 12 compartments were analyzed for the quantification the physical and chemical properties of the floodplains' sediments. The physical properties analyzed were the particle size distribution (sand, silt and clay fractions), while the chemical properties were $\mathrm{pH}, \mathrm{TN}, \mathrm{TP}, \mathrm{TK}$, and TOC. The nutrient analysis yielded proportional figures to the sediment masses. The analytical methods are listed in Table 2. 


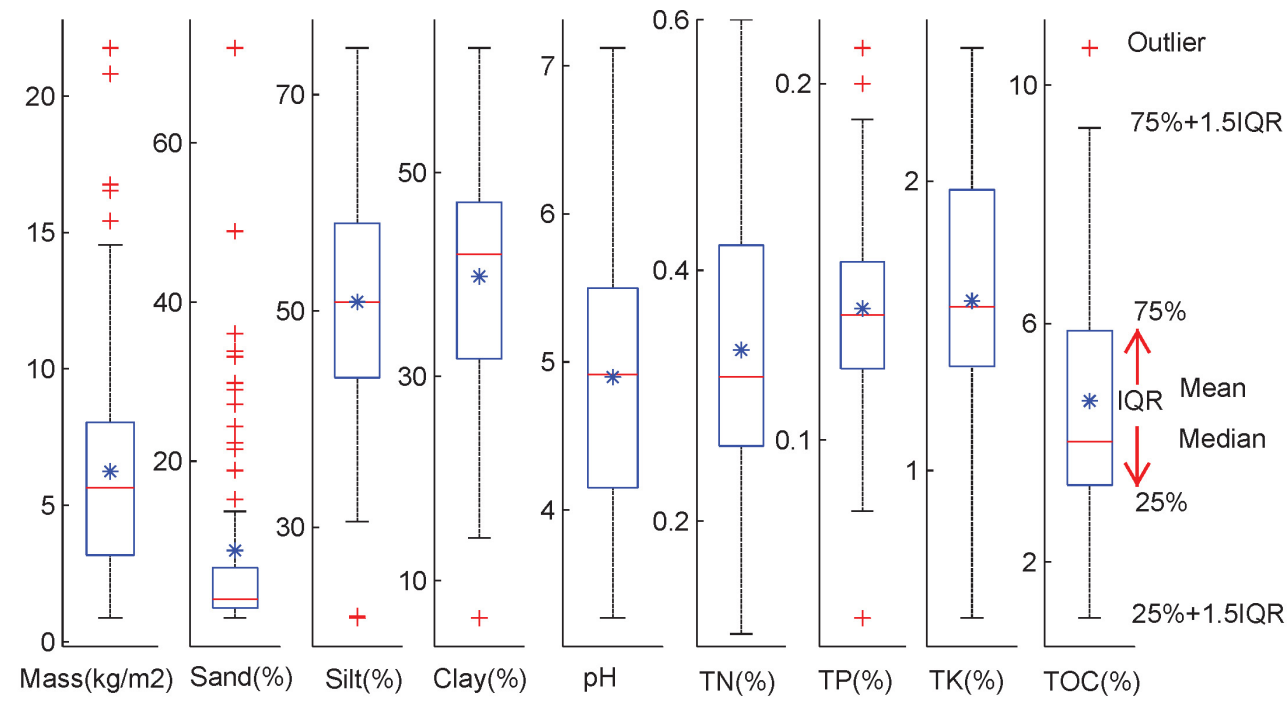

Fig. 7. Box plots of all data: sediment mass (g), sediment grain size classification of sand, silt and clay (\%), potential hydrogen (pH), and the percentage $(\%)$ of TN, TP, TK and TOC.

Figure 7 presents the analysis results and their overall variability for all analyzed samples in box-whisker-plots. Sediment masses show a high variability with minimum and maximum deposition of 1.44 and $21.7 \mathrm{~kg} \mathrm{~m}^{-2}$ respectively, while the median deposition is $6.0 \mathrm{~kg} \mathrm{~m}^{-2}$. This high variation is expressed in a high overall coefficient of variation of 0.64 . The variability of the nutrient fractions is considerably lower. Minimum and maximum values are always in the same order of magnitude, and the coefficients of variation are 0.36 , $0.21,0.28$ and 0.44 for TN, TP, TK and TOC, respectively. This finding supports the hypothesis that the nutrient content of the sediment is relatively uniformly distributed over the delta and that the spatial differences in nutrient input to the floodplains is mainly controlled by the deposition masses, and only to a minor extent by variable nutrient content of the sediments.

For $\mathrm{pH}$ extreme values up to 3.2 and slightly alkaline samples are observed. The grain size distribution is dominated by the silt and clay fractions with only little and sporadic sand components, as the low percentages and high number of outliers of the sand fraction showed. The coefficients of variation are $0.2,0.22,0.17$ and 1.53 for silt, clay, $\mathrm{pH}$ and sand respectively. This is typical for suspended sediment in the MD (Wolanski et al., 1996; Thuyen et al., 2000; Hung et al., 2013a).

Figure 8 shows the variability of each of the 49 sample clusters' deposition mass derived from the sampling repetitions, and for the 12 compartment-wise collected samples for the remaining parameters. The different data aggregation levels, i.e., trap cluster for deposition mass and compartments for the remaining parameters, acknowledge the higher variability of the deposition mass and the quantification of the remaining parameters in relative terms, which is to a large extent independent of the actual deposition mass at a single monitoring point. For all parameters, mean, SD, and CV are plotted. The clusters, respective compartment samples, are sorted according to the mean. The standard deviations are always smaller than the mean resulting in CVs below 1 . The deposition mass data shows an interesting trend in declining variability of $\mathrm{CV}$ with mean deposition, indicating that the sampling uncertainty is smaller with higher deposition masses. This can be explained by the fact that even little disturbances can have a large effect on deposition in case of only small deposition volumes. For all other parameters besides deposition mass except the sand fraction, the variation within the compartments is comparatively low, as the small CV's indicate (Fig. 8). This corroborates the finding that the nutrient content shows only little spatial variation, both within compartments and over the complete sampled domain. These findings imply that (a) the deposition masses contain significant high uncertainties that should be quantified, and (b) the focus of an uncertainty analysis should be laid on the uncertainty in deposition mass, as this also influences the uncertainty in the estimation of the absolute nutrient deposition.

\subsection{Uncertainty analysis}

In this section the differences in the derived uncertainty estimates from steps 4,7 , and 9 are discussed. Table 3 shows a ranking of the parameters by relative uncertainty to the mean based on the the upper bounds of the confidence intervals. The sand fraction has the largest uncertainty bounds with the maximum range from 65 to $203 \%$, while the smallest bounds are found for $\mathrm{pH}$ with $36 \%$ to both sides. The nutrient mass bounds are significantly wider than the bound of sediment mass, because the uncertainty of the sediment mass 

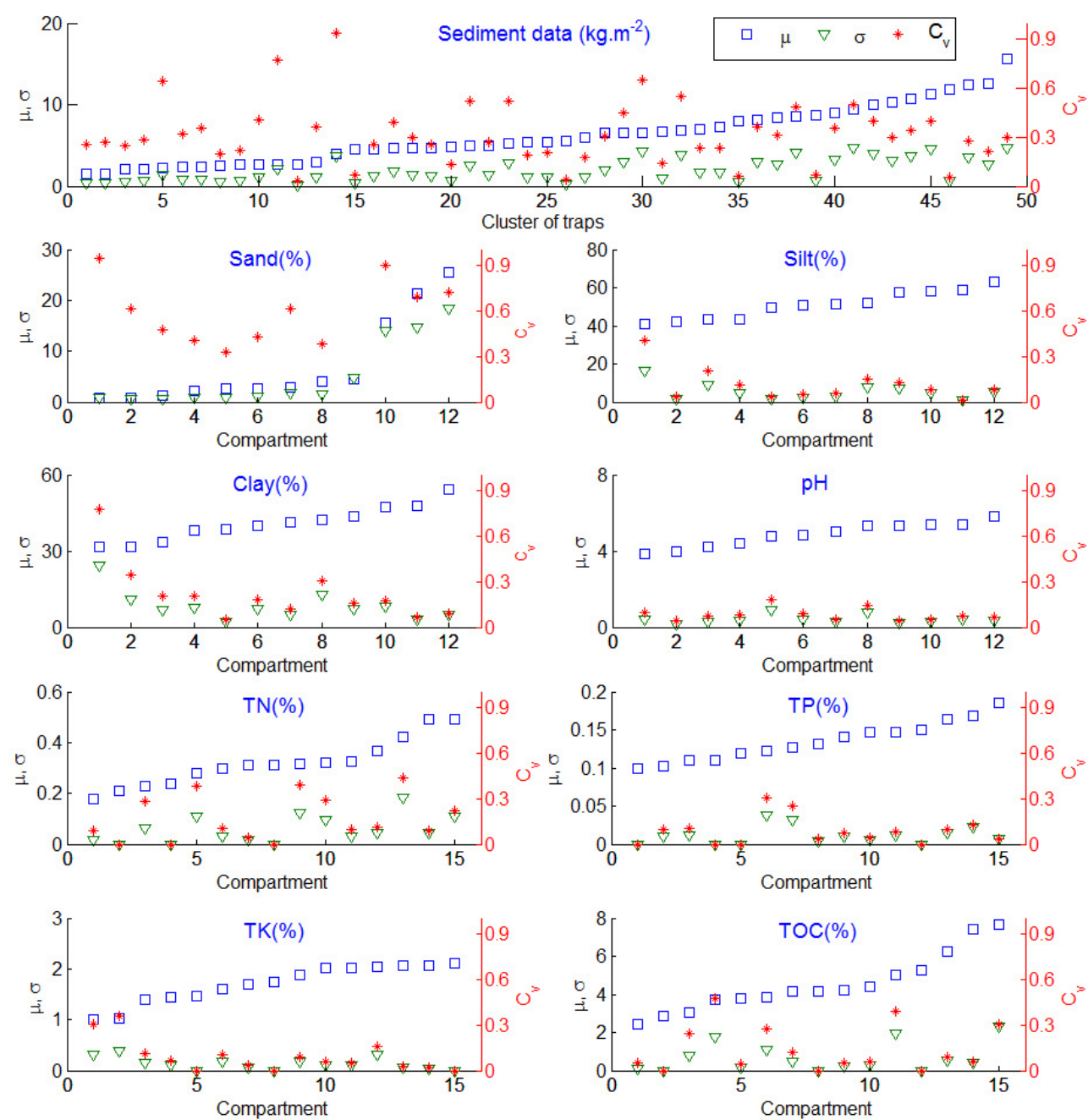

Fig. 8. The means $(\mu)$, standard deviations $(\sigma)$ and coefficient of variation of sediment weight on cluster traps, $\mathrm{pH}$ and nutrient data in compartments.

is enlarged by the uncertainty of the nutrient fractions. Silt and clay have quite narrow bounds in terms of their mean, ranging from 39 to 43 and $22 \%$ on both sides respectively.

Figure 9 shows the mean and $95 \%$ CI of deposited sediment mass before and after the MC analysis, sorted by the measured mean original deposition mass. Overall, the uncertainty bounds are asymmetric due to the constraint from Eq. (2). In relative terms the lower bound is always less or at least equal to the upper bound. The single samples show higher uncertainty ranges compared to cluster traps with approximately equal mass. Overall it can be observed that the uncertainty bounds can be considerably large, with a maximum of relative lower bound of $61 \%$ and and a relative upper bound of $129 \%$. The minimum relative bounds are 14 (upper) to $21 \%$ respectively (lower), cf. Table 3 . There is a trend towards higher uncertainty with higher sediment mass. This has to be attributed to the wet-dry sampling uncertainty, because this is larger for larger deposition masses (cf. Sect. 3.3.1) and the deposition sampling uncertainty does not show this trend, rather the opposite. If the deposition sampling uncertainty is low, the overall uncertainty is also well constrained in narrow CIs. The lower CI is closer to the mean and less variable due to the constraint in the wet-dry sampling correction.

In Fig. 10, the uncertainty bounds of deposited nutrients $\left(\mathrm{g} \mathrm{m}^{-2}\right)$ are propagated from sediment weight bounds based on the analyzed nutrient fractions (\%). Therefore, the uncertainty bounds show the same characteristics as for the sediment masses (Fig. 10). Due to the additional uncertainty of the nutrient fraction, the relative uncertainty is increased for the nutrient deposition estimates. These features are illustrated in Table 3. The upper confidence bounds of nutrient masses are 5-10\% larger compared to sediment for the lower bounds and 10-20\% for the upper bounds.

In contrast to the nutrients, the grain size fractions and $\mathrm{pH}$ show different uncertainty characteristics, as they do not 
Table 3. Uncertainty rank (sorted from low to high mean upper CI) of sediment mass $\left(\mathrm{kg} \mathrm{m}^{-2} \mathrm{yr}^{-1}\right)$, nutrient mass $\left(\mathrm{g} \mathrm{m}^{-2} \mathrm{yr}^{-1}\right)$, grain size (\%) and $\mathrm{pH}$. The uncertainty is expressed as $95 \% \mathrm{CI}$ of PDFs.

\begin{tabular}{|c|c|c|c|c|c|c|c|c|c|}
\hline \multirow[b]{2}{*}{ Rank } & \multirow[b]{2}{*}{ Component } & \multicolumn{2}{|c|}{ Mean PDFs } & \multicolumn{3}{|c|}{ Lower CIs } & \multicolumn{3}{|c|}{ Upper CIs } \\
\hline & & $\min$ & $\max$ & $\min$ & mean & $\max$ & $\min$ & mean & $\max$ \\
\hline 1 & Sand & 0.8 & 25.5 & $65 \%$ & $91 \%$ & $100 \%$ & $65 \%$ & $123 \%$ & $203 \%$ \\
\hline 2 & TOC & 122.4 & 3109.3 & $30 \%$ & $44 \%$ & $65 \%$ & $58 \%$ & $105 \%$ & $168 \%$ \\
\hline 3 & $\mathrm{TN}$ & 8.3 & 216.0 & $27 \%$ & $42 \%$ & $64 \%$ & $49 \%$ & $98 \%$ & $155 \%$ \\
\hline 4 & TK & 38.0 & 990.1 & $24 \%$ & $40 \%$ & $63 \%$ & $43 \%$ & $91 \%$ & $153 \%$ \\
\hline 5 & $\mathrm{TP}$ & 3.1 & 84.3 & $21 \%$ & $38 \%$ & $62 \%$ & $40 \%$ & $85 \%$ & $139 \%$ \\
\hline 6 & Sed. mass & 2.2 & 60.6 & $14 \%$ & $35 \%$ & $61 \%$ & $21 \%$ & $73 \%$ & $129 \%$ \\
\hline 7 & Clay & 31.4 & 54.2 & $10 \%$ & $39 \%$ & $100 \%$ & $10 \%$ & $43 \%$ & $152 \%$ \\
\hline 8 & Silt & 40.7 & 63.1 & $2 \%$ & $22 \%$ & $80 \%$ & $2 \%$ & $22 \%$ & $80 \%$ \\
\hline 9 & PH & 3.9 & 5.8 & $9 \%$ & $16 \%$ & $36 \%$ & $9 \%$ & $16 \%$ & $36 \%$ \\
\hline
\end{tabular}

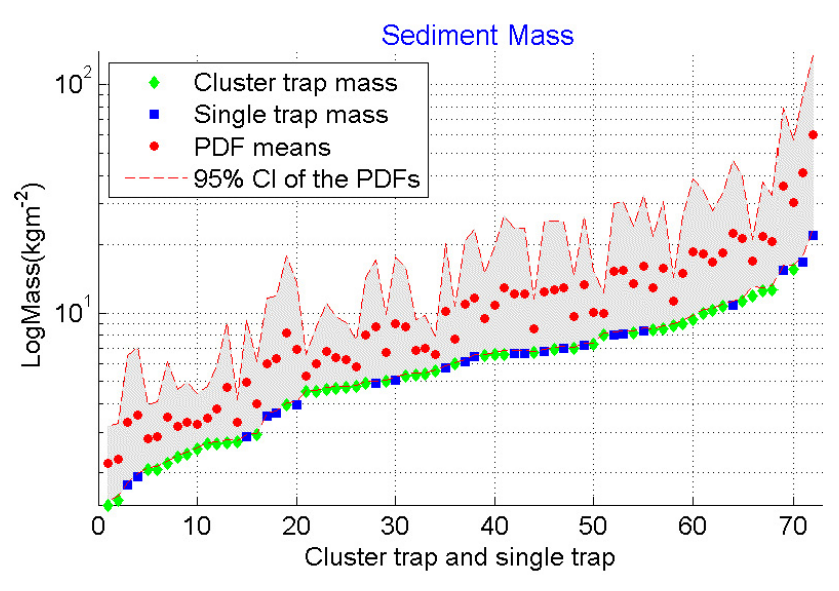

Fig. 9. Mean (red dots) and confidence intervals (red dash line) of sediment mass after wet-dry sampling correction and uncertainty analysis, and original trap data. Sediment masses with indication of cluster and single trap samples.

depend on the deposition mass (Fig. 11). The confidence intervals are small compared to sediment mass and nutrients and essentially symmetric, which is a consequence of the assumption of normal distributed deposition uncertainty. The sand fraction has the highest uncertainty for large sand fraction values, illustrating the sporadic and most likely locally influenced sand content of the suspended sediments in the VMD. The opposite holds true for the clay fraction, where the uncertainty is highest for low clay fractions. This effect has to be attributed to the small particle size and the related sensitivity of the laboratory analysis of the clay fraction, but also to the slow settling of the particles and susceptibility to only minor hydraulic disturbances and temperature (Hung et al., 2013a).

\subsection{Sedimentation and nutrient deposition rates}

For an assessment of the deposition rates we use the mean values from the uncertainty analysis. Across all study sites, the sedimentation rates varied from $2.2-60.6 \mathrm{~kg} \mathrm{~m}^{-2} \mathrm{yr}^{-1}$ in the mean, equivalent to $1.8-50.5 \mathrm{~mm} \mathrm{yr}^{-1}$. The mean rate equals $9.5 \mathrm{~mm} \mathrm{yr}^{-1}$ based on a dry bulk density of $1.2 \mathrm{t} \mathrm{m}^{-3}$ (Xue et al., 2010). The nutrient rates are proportional to the sedimentation rates. TOC has the highest rate: the maximum rate is close to $3110 \mathrm{~g} \mathrm{~m}^{-2} \mathrm{yr}^{-1}$ and the mean rate is about $611 \mathrm{~g} \mathrm{~m}^{-2} \mathrm{yr}^{-1}$. The mean rates of TN, TP and TK are 42,16 , and $192 \mathrm{~g} \mathrm{~m}^{-2} \mathrm{yr}^{-1}$ respectively. Table 4 provides an overview of the sedimentation rates over all study sites and in low dike and high dike systems. Differentiating the results in low and high dike compartments, it can be shown that the maximum sediment and nutrient deposition in low dike compartments triples the maximum rate in high dike compartments (Table 4). Also the minimum values are more extreme in the low dike compartments. However, the average values are 11.6 and $10.6 \mathrm{~kg} \mathrm{~m}^{-2} \mathrm{yr}^{-1}$ in low and high dike systems, respectively. This indicates that on average no significant difference between low and high dike systems could be observed, but the variability in deposition is considerably higher in the low dike compartments $\left(2.2-60.6 \mathrm{~kg} \mathrm{~m}^{-2} \mathrm{yr}^{-1}\right)$ compared to the high dikes $\left(4.7-18.4 \mathrm{~kg} \mathrm{~m}^{-2} \mathrm{y}^{-1}\right)$. This is a consequence of the different hydraulic links between the channels and the floodplains of the different dike systems (Hung et al., 2012). However, in the interpretation of these results the severity of the flood in 2011 has to be taken into account. The high flood peak and long inundation duration likely reduced the differences in floodplain inundation between the two dike systems.

The differences in grain size distribution between low and high dikes are little, although there is a slight tendency that the low dike compartments exhibit a higher overall variability (Table 4). This can be explained by the generally higher flow in the low dike compartments, which are hydraulically fully connected to the channels, whereas the flow in the high 

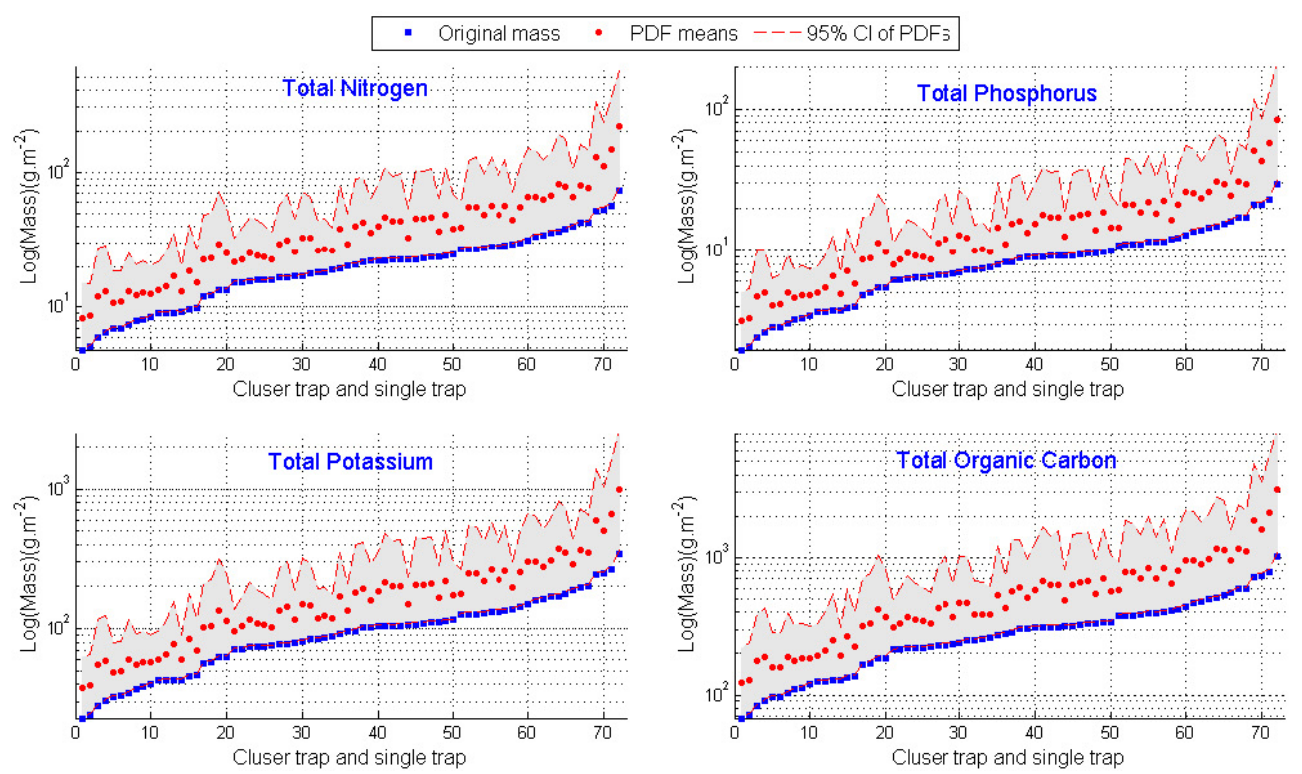

Fig. 10. Mean (red dots) and confidence intervals (red dashed lines) of nutrient masses after wet-dry sampling correction and uncertainty analysis, compared to the original sampled masses.
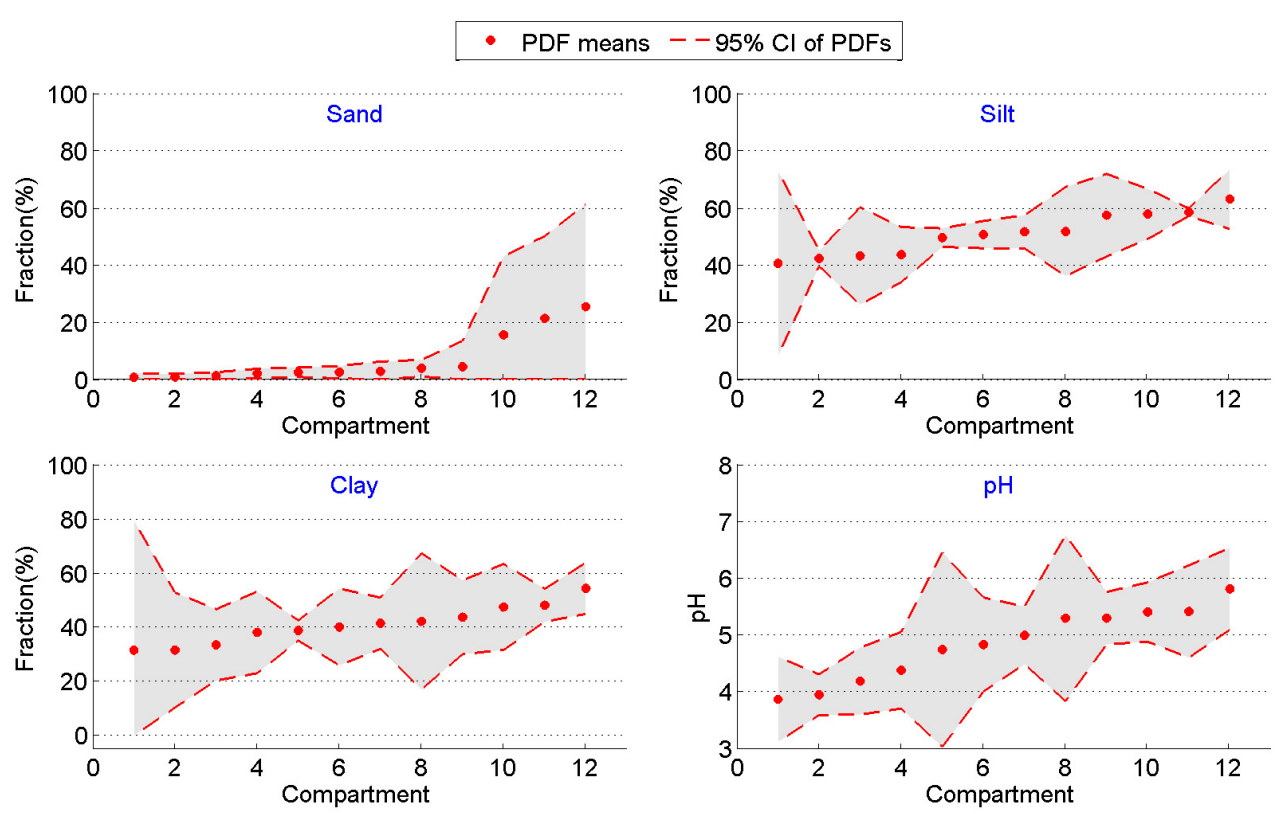

Fig. 11. Mean (red dots) and confidence intervals (CI, red dash lines) of sand fraction, silt fraction, clay fraction and $\mathrm{pH}$.

dike compartments is controlled and limited by the sluice gate capacities.

The low $\mathrm{pH}$ values in Table 4 can be explained by the acid sulphate soils found in large parts of the MD floodplains. The total acid soil area is $1.1 \times 10^{6}$ ha over a total $1.8 \times 10^{6}$ ha in the floodplain area, i.e., about $60 \%$ of the floodplains have acid soils (soil map - MONRE $^{1}$ ). Moreover, the extraordinary inundation in 2011 in combination with re-suspension

\footnotetext{
${ }^{1}$ Ministry of Natural Resources and Environment of Vietnam.
}

processes might have caused a further reduction in $\mathrm{pH}$ in sediment samples.

In order to compare and interpret these figures a comparison with the Yangtze Delta is conducted (Table 5). The average suspended sediment concentration (SSC) in the MD and the Yangtze Delta is approximately identical in terms of maximum monthly SSC. The silt and clay grain fractions account for more than $95 \%$ with an average of about $40 \%$ clay. This is equivalent to published data of the Yangtze Delta (Table 5). The similarities between the Mekong and the Yangtze might 
Table 4. Mean, minimum and maximum values of sediment and nutrient deposition rates over all study sites, and separated for different spatial units: low dike, high dike, Plain of Reeds, and Long Xuyen Quadrangle in the 2011 flood.

\begin{tabular}{|c|c|c|c|c|c|c|c|c|c|c|c|}
\hline & & $\mathrm{Sec}$ & ment & $\mathrm{TN}$ & $\mathrm{TP}$ & TK & TOC & Sand & Silt & Clay & \\
\hline Spati & unit & $\left(\mathrm{kg} \mathrm{m}^{-2}\right)$ & $\left(\mathrm{mm} \mathrm{yr}^{-1}\right)$ & & & $\left.a^{-2}\right)$ & & & $(\%)$ & & $\mathrm{pH}$ \\
\hline Overall & Min & 2.2 & 1.8 & 8 & 3 & 38 & 122 & 0.8 & 40.7 & 31.4 & 3.9 \\
\hline & Mean & 11.4 & 9.5 & 42 & 16 & 192 & 611 & 7.0 & 50.9 & 40.8 & 4.8 \\
\hline & Max & 60.6 & 50.5 & 216 & 84 & 990 & 3109 & 25.5 & 63.1 & 54.2 & 5.8 \\
\hline Low & Min & 2.2 & 1.8 & 8 & 3 & 38 & 122 & 0.8 & 40.7 & 31.4 & 4.0 \\
\hline dike & Mean & 11.6 & 9.7 & 43 & 17 & 196 & 623 & 5.7 & 50.3 & 42.3 & 4.9 \\
\hline & $\operatorname{Max}$ & 60.6 & 50.5 & 216 & 84 & 990 & 3109 & 21.4 & 58.5 & 54.2 & 5.8 \\
\hline High & Min & 4.7 & 3.9 & 17 & 7 & 78 & 251 & 2.6 & 43.2 & 31.5 & 3.9 \\
\hline dike & Mean & 10.6 & 8.9 & 40 & 15 & 180 & 575 & 10.8 & 52.7 & 36.1 & 4.7 \\
\hline & $\operatorname{Max}$ & 18.4 & 15.3 & 68 & 26 & 309 & 978 & 25.5 & 63.1 & 43.6 & 5.4 \\
\hline
\end{tabular}

Table 5. Sediment characteristics of the Mekong and Yangtze at their deltas.

\begin{tabular}{llllll}
\hline River & $\begin{array}{l}\text { Length/Area } \\
\left(\mathrm{km} / 10^{3} \mathrm{~km}^{2}\right)\end{array}$ & $\begin{array}{l}\text { TDS/TSS } \\
\left(10^{6} \mathrm{t} \mathrm{yr}^{-1}\right)\end{array}$ & $\begin{array}{l}\text { Average of } \\
\text { max monthly SSC }\end{array}$ & $\begin{array}{l}\text { Grain size } \\
(\%)\end{array}$ & $\begin{array}{l}\text { Sedimentation } \\
\left(\mathrm{cm} \mathrm{yr}^{-1}\right)\end{array}$ \\
\hline Mekong & $4800 / 800^{\mathrm{a}}$ & $60 / 110(150)^{\mathrm{a}}$ & $\begin{array}{l}0.326 \mathrm{~kg} \mathrm{~m}^{-3} \\
\text { Tan Chau station }\end{array}$ & $\begin{array}{l}7 \% \text { sand, 51\% silt, } \\
4 \% \text { clay }\end{array}$ & $0.18-5.0$ \\
\hline Yangtze & $6300 / 1800^{\mathrm{a}}$ & $180 / 470^{\mathrm{a}}$ & $0.292 \mathrm{~kg} \mathrm{~m}^{-3, \mathrm{~b}}$ Xuliujing station & $\begin{array}{l}5 \% \text { sand, } \\
40-45 \% \text { clay, } \\
40-60 \% \text { silt }\end{array}$ & $1.4-2.5^{\mathrm{d}}$ \\
\hline
\end{tabular}

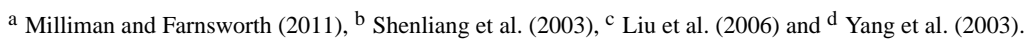

me partially explained by their shared origin in the Tibetan plateau.

A comparison of floodplain sedimentation in these deltas is difficult as hardly any data are available. However, a comparison with the published sedimentation rate in the Yangtze Delta shows that the average sedimentation rate in the MD is similar to the result in the Yangtze Delta, but showing a larger variability. This may be interpreted as an impact of the intensive fragmentation of floodplains in the MD, but may as well be an artifact of the data collection and interpretation.

\subsection{Spatial variability of sedimentation}

The spatial distribution of floodplain sedimentation is controlled by the channel and dike systems in the VMD. The channel system is classified as follows: the main channels are "large" channels conveying floods from Tien River and Hau River through the delta and the associated dikes are typically combined with provincial roads (high dikes). The secondary channels are "medium" channels branching from the main channels and creating compartments (high dikes or low dikes). Within these large compartments inner "small" channels exist. These channels are used for agricultural transportation and drainage, and are accompanied by low dikes, if at all.

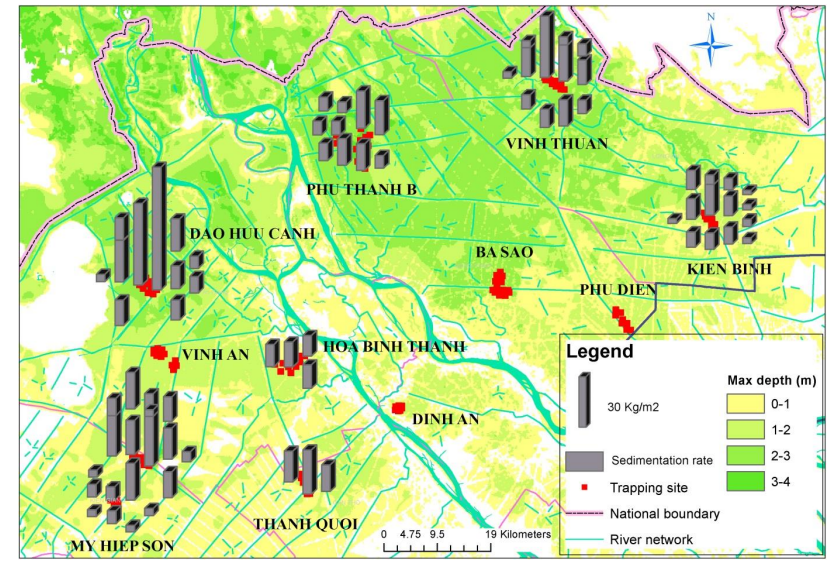

Fig. 12. Mean sedimentation rate (grey columns) of all monitoring points.

Normally, a compartment in the Mekong floodplains consists of a secondary ring channel accompanied with high dikes or low dikes, some inner channels with its banks, sluice gates, open culverts, and pumping stations. The flood water from the rivers flows into the channel network and is then redistributed into compartments through hydraulic structures for high dike systems or overflows into compartments in 


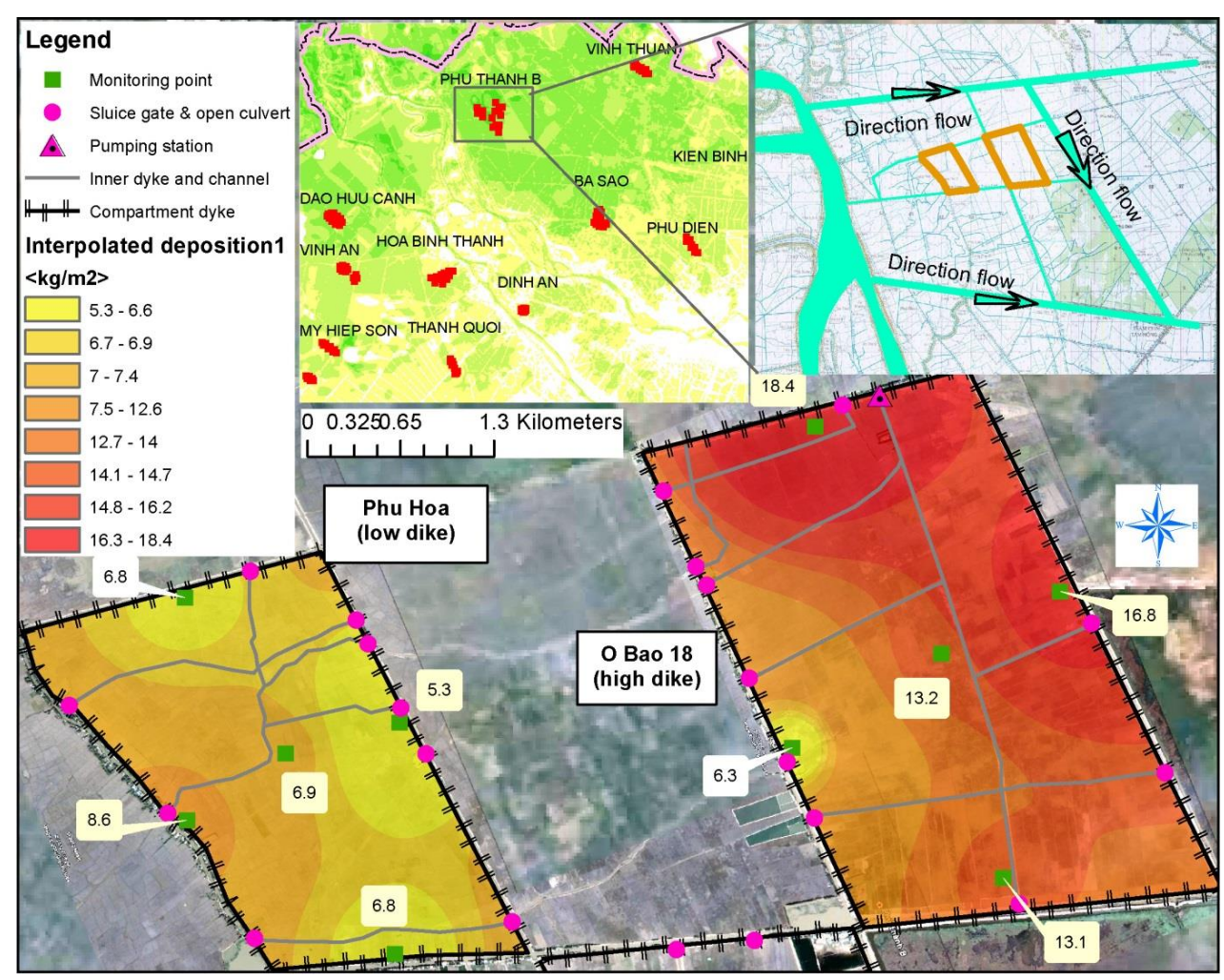

Fig. 13. Spatial distribution of sedimentation in two nearby compartments in the Phu Thanh B sites.

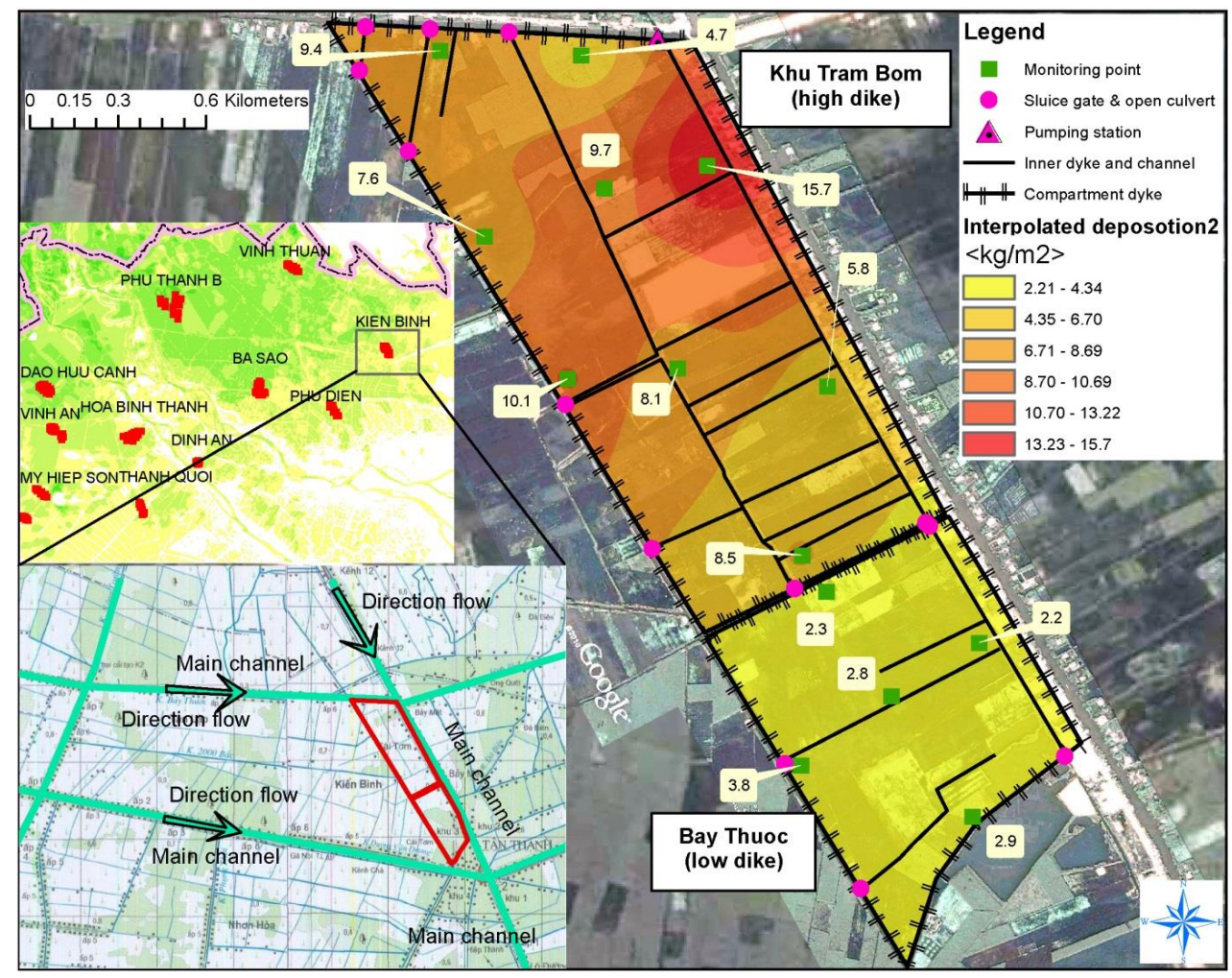

Fig. 14. Spatial distribution of sedimentation in two adjacent compartments in the Kien Binh site - Long An. 


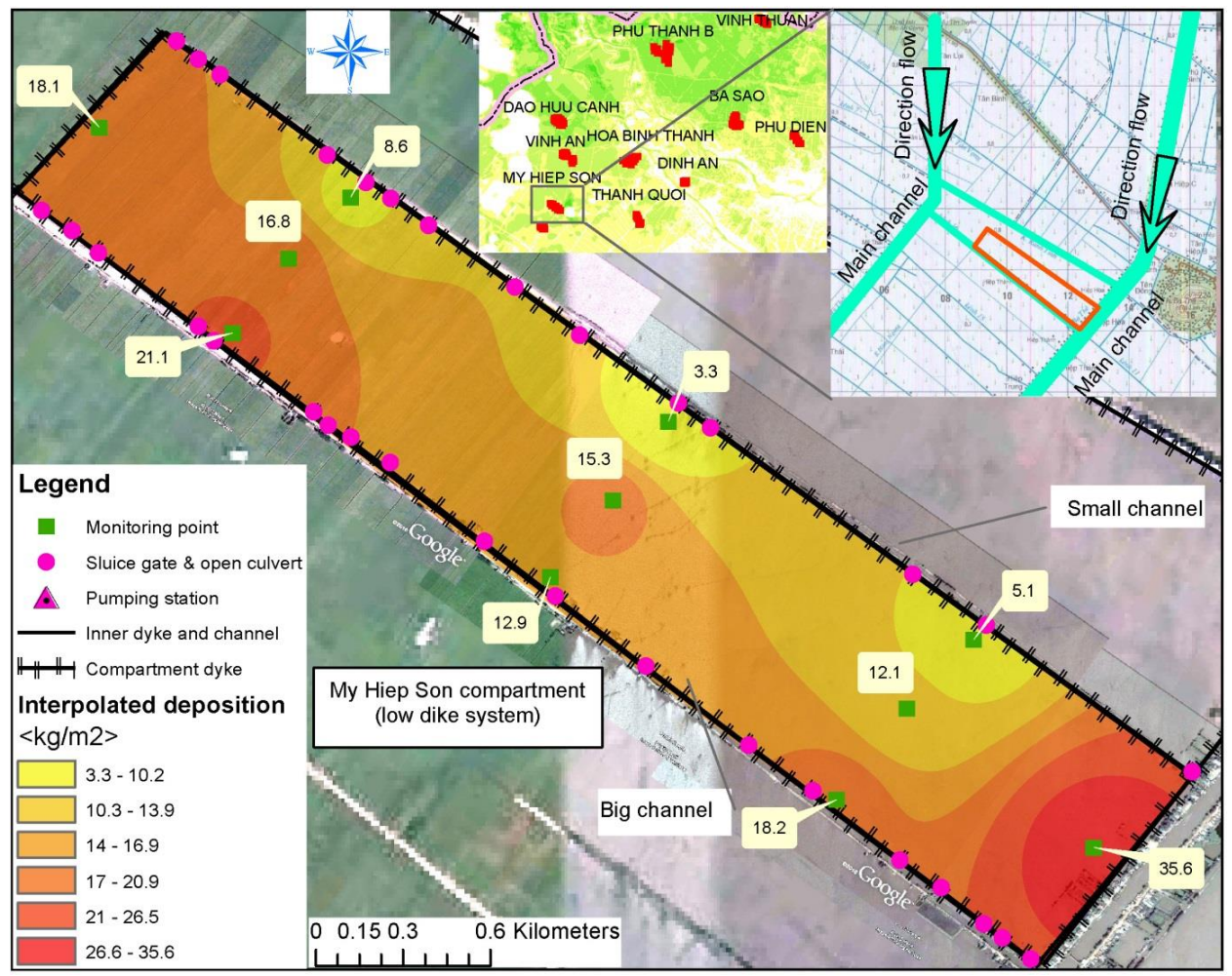

Fig. 15. The typical pattern of high sedimentation variability in low dike compartments in My Hiep Son - Kien Giang.

"high stage" in low dike systems (Hung et al., 2012). The sediment movement into compartments includes advective transport with flow (primary transportation) and an additional but small dispersive component. This means that theoretically the low dike compartments potentially have a higher chance to receive a higher sedimentation than the high dike, as the flow into the compartment is less restricted and the flow velocity is higher on average. However, as this and a previous study (Hung et al., 2012) indicate, a clear distinction of the floodplain sedimentation between the different dike systems cannot be found. The complex interplay of inundation dynamics, channel and dike systems, and the high number of hydraulic structures creates a differentiated sedimentation pattern without obvious correlations or patterns (Fig. 12).

A spatial interpolation of the derived sedimentation data is thus not performed over the whole VMD, but compartmentwise. Inverse distance weighting (IDW) interpolation was applied on the mean values. Figure 13 shows exemplarily the Phu Thanh site. Both compartments are located in the center of a main channel ring with a lot of secondary channels and inner channels. The mean sedimentation rate with uncertainty bounds in the high dike O Bao 18 compartment of $14.6(9.0-22.5) \mathrm{kg} \mathrm{m}^{-2} \mathrm{yr}^{-1}$ is significantly higher than that in the nearby low dike Phu Hoa compartment 6.3 (4.9$8.9) \mathrm{kg} \mathrm{m}^{-2} \mathrm{yr}^{-1}$. Also the spatial variability within the compartment is in this case higher in the high dike compartment than in the low dike compartment. This seems to be
Table 6. Mean sedimentation values $\left(\mathrm{kg} \mathrm{m}^{-2} \mathrm{yr}^{-1}\right)$ in different spatial units: low dike and high dike, Plain of Reeds/Long Xuyen Quadrangle and whole VMD.

\begin{tabular}{lrrr}
\hline $\begin{array}{l}\text { Mean } \\
\text { sedimentation }\end{array}$ & $\begin{array}{r}\text { Whole } \\
\text { VMD }\end{array}$ & $\begin{array}{r}\text { Plain of } \\
\text { Reeds }\end{array}$ & $\begin{array}{r}\text { Long Xuyen } \\
\text { Quadrangle }\end{array}$ \\
\hline Overall & 11.4 & 9.1 & 14.0 \\
Low dike & 11.6 & 8.2 & 14.0 \\
High dike & 10.6 & 10.5 & 12.0 \\
\hline
\end{tabular}

contradictory to the postulated higher general variability in low dike compartments, but can be explained by the fact that locally, i.e., in a compartment, the spatial deposition in high dike compartments is influenced to a large extent by the position and operation of the sluice gates. From these results of these two compartments a slight trend towards lower deposition in the center of the floodplain between the main channels could be postulated, but as data from the surrounding compartments are missing, this cannot be corroborated.

A similar result can be found in the Kien Binh site (Fig. 14), where a high dike system in the Khu Tram Bom compartment and a low dike in the Bay Thuoc compartment were monitored. Both compartments are located next to a main channel, but have different sediment sources (inundation paths) that lead to completely different sedimentation patterns and values. The average sedimentation 
rate in the Khu Tram Bom compartment (high dike) is $8.7 \mathrm{~kg} \mathrm{~m}^{-2} \mathrm{yr}^{-1}$ with an associated uncertainty bound of (6.3-12.5) $\mathrm{kg} \mathrm{m}^{-2} \mathrm{yr}^{-1}$ and much smaller in the Bay Thuoc compartment (low dike) with $2.6(2.0-3.5) \mathrm{kg} \mathrm{m}^{-2} \mathrm{yr}^{-1}$. It can be seen, that higher sedimentation rates are closer to sediment sources, i.e., the sluice gates connecting the floodplain to the main and secondary channels.

Figure 15 shows the interpolated deposition in the My Hiep Son compartment. This shows contrary to the previous examples a high variability of sedimentation rates in a low dike compartment. The values of minimum and maximum rates are $3.3(1.9-7.5) \mathrm{kg} \mathrm{m}^{-2} \mathrm{yr}^{-1}$ and 35.6 (17.1$56.4) \mathrm{kg} \mathrm{m}^{-2} \mathrm{yr}^{-1}$, respectively, compared to 16.1 (9.126.6) $\mathrm{kg} \mathrm{m}^{-2} \mathrm{yr}^{-1}$, the average rate of this compartment. The $\mathrm{CV}$ is with a value of 0.5 in this compartment significantly higher than CVs in high dike compartments. This has very likely to be attributed to the better hydraulic linkage to a main channel as compared to the previous examples.

Table 6 shows the mean values of sedimentation in different larger spatial units, i.e., regions of the VMD. In this analysis, the Long Xuyen Quadrangle receives a higher mean sediment deposition as the Plain of Reeds (cf. Fig. 1). However, the deposition within high dike compartments is on the mean comparable between the two regions, but the monitored low dike compartments receive considerably less sediments in the Plain of Reeds, explaining the differences in the overall deposition. Interestingly, if averaged over the whole study regions, the mean deposition in high and low dikes is again comparable. An interesting aspect of this analysis is that over the whole VMD the deposition in low dike compartments shows a higher variability between the compartments, i.e., varies higher between the regions of the VMD compared to the high dike compartments, but within compartments the spatial variability is higher in the high dike compartments. In summary, the results and examples presented above suggest that the fragmentation of the floodplains by the channel and dike systems destroyed the natural consistency and continuity of the floodplains in the Mekong Delta not only hydraulically, but also in terms of floodplain sedimentation.

\section{Conclusions}

This study proposes a procedure to monitor quantity and spatial variability of sediment and associated nutrient deposition in large and complex river floodplains including an uncertainty analysis. The uncertainty estimation consists of the (1) trap installation in clusters to quantify the deposition sampling uncertainty, (2) trap retrieval test to quantify losses by sample collection from inundated floodplains, and (3) a Monte Carlo framework for estimating uncertainty bounds from these uncertainty sources.

This methodology is applied in a large-scale study in the Vietnamese Mekong Delta. The mean sediment deposition $11.4 \mathrm{~kg} \mathrm{~m}^{-2}$ is equivalent to $9.5 \mathrm{~mm} \mathrm{yr}^{-1}$. This figure is comparable to published values for the Yangtze Delta, which has the same geographical origin as the Mekong. The related mean deposition of nutrients is $42 \mathrm{~g} \mathrm{~m}^{-2}$ total nitrogen, $16 \mathrm{~g} \mathrm{~m}^{-2}$ total phosphorous, $192 \mathrm{~g} \mathrm{~m}^{-2}$ total potassium and $611 \mathrm{~g} \mathrm{~m}^{-2}$ total organic carbon. The sediments are constituted mainly by silt and clay, with little and only sporadic sand proportions. The sediments are generally acidic with an overall mean value of $\mathrm{pH} 4.8$.

The derived $95 \%$ uncertainty bounds of the sediment deposition mass range from -61 to $+129 \%$ of the mean values for the entire dataset. The nutrient deposition uncertainty is slightly larger, as it directly depends on the sedimentation mass, but the determination of the nutrient content adds another uncertainty source. The uncertainties associated to grains sizes and $\mathrm{pH}$ are considerably smaller, as they are hardly affected by uncertainties in deposition mass. In addition these properties generally do not show a large spatial variation in contrast to the sediment and nutrient deposition. The sand fraction is the only exception in this respect. This finding can be attributed to the fact that the sand fraction in floodplain deposits is generally low and highly influenced by local relocation processes. The sediment source, i.e., the suspended sediment in the Mekong Delta, contains only a very small sand fraction.

The main uncertainty sources are the trap retrieval from still inundated floodplains and likely human interference on the floodplains and floodplain inundation. While the sediment retrieval uncertainties are systematic and quantifiable, the variability caused by human interference and small-scale differences in deposition and re-suspension is an uncertainty source that is difficult to attribute to distinct factors. Human interference ranges from direct impact on the sedimentation, by e.g., disturbances, by fishing on the floodplains with nets, to indirect causes by regulating floodplain inundation by sluice gate control and operation of pumps. For the monitoring of floodplain inundation local actions to restrict fishing activities could help, although this is almost impossible to enforce.

Mean sediment deposition values are highly variable, both for the whole set of monitoring points and among the different compartments. The variability among the compartments cannot be attributed to the dike system (low crop protection dikes or high flood protection dikes), as the differences in mean deposition is negligible. However, the mean deposition in low dike compartments showed a higher spatial variability compared to the high dike compartments if analyzed over the whole Vietnamese Mekong Delta, indicating the normalizing influence of the controlled floodplain inundation in the high dike compartments. In contrast to these findings, the spatial variability within individual compartments tends to be higher in high dike compartments, as the sediment source as well as the flow in the compartments are controlled by the location and operation of the sluice gates. Both source and flow can be assumed to be more homogeneous within low dike compartments leading to less spatial variability of in-department 
deposition. A noticeable influence on floodplain deposition seems to be the distance of the floodplain compartments to the main channels and the location and number of sluice gates. This corresponds to the findings of Hung et al. (2013b) gained in a small test site in the Plain of Reeds of the Mekong Delta.

All findings have to be interpreted in combination with the extraordinary flood in the study year 2011, for which peak flow and duration were the second largest in the observation period of about $80 \mathrm{yr}$. Hence, the observed sedimentation may not be representative for the typical flood situation in the Vietnamese Mekong Delta. We expect that during normal flood years the differences between the low and high dike systems are more pronounced. Therefore, a repetition of the measurement campaign would not only provide additional statistical significance to the presented results, but potentially also lead to a better understanding of the impact of the dike systems on floodplain sedimentation in the Vietnamese Mekong Delta by either corroborating or contrasting the presented results..

Because of the observed low spatial correlation of the floodplain sedimentation over the entire region, an interpolation of the point samples to a large-scale floodplain sedimentation map is not feasible. The derived data are lacking the required autocorrelation and meaningful variograms for geostatistical interpolation. Potentially, a large-scale spatial estimation of floodplain deposition could be derived via remote sensing. Optical satellite products can quantify suspended sediment concentrations, from which the deposition could be inferred. The problem with this approach is the high cloud cover during the flood/monsoon period. Therefore, a spatial estimation of floodplain sedimentation has to rely on numerical simulation of the floodplain hydraulics and deposition processes, for which the derived data and uncertainty estimates can provide the essentially required calibration data. Consequently this will be the next step in our analysis of the floodplain sedimentation of the VMD.

In light of the results and experiences gained in the present study the following recommendations for floodplain sedimentation monitoring in the Vietnamese Mekong Delta can be derived: the number of monitoring points in the floodplain compartments should be defined according to the floodplain topography, number and location of flood control structures and the presented sedimentation patterns in different floodplains. In rectangular, small compartments $(<100$ ha $)$ with one sluice gate on each side, at least 5 monitoring points on 4 sides and in the center of the compartment should be placed to capture the general sedimentation pattern. In larger compartments ( $>100$ ha) with several sluice gates on each side the minimal number of monitor points should be proportional to the number of main sluice gates and the compartment area. As the fishing activity on the floodplains proved to be a major threat for the monitoring, negotiations and collaboration with not only the land owner but also the local community is essential to protect installed traps.
Acknowledgements. The presented work was performed within the project WISDOM - Water related Information System for a Sustainable Development of the MD (www.wisdom.eoc.dlr.de). Funding by the German Ministry of Education and Research BMBF and the Vietnamese Ministry of Science and Technology is gratefully acknowledged.

The service charges for this open access publication have been covered by a Research Centre of the Helmholtz Association.

Edited by: E. Gargouri-Ellouze

\section{References}

Apel, H., Thieken, A. H., Merz, B., and Blöschl, G.: Flood risk assessment and associated uncertainty, Nat. Hazards Earth Syst. Sci., 4, 295-308, doi:10.5194/nhess-4-295-2004, 2004.

Apel, H., Thieken, A. H., Merz, B., and Blöschl, G.: A Probabilistic Modelling System for Assessing Flood Risks, Nat. Hazards, 38, 79-100, doi:10.1007/s11069-005-8603-7, 2006.

Apel, H., Merz, B., and Thieken, A. H.: Quantification of uncertainties in flood risk assessments, International Journal of River Basin Management, 6, 149-162, 2008.

Asselman, N. E. M. and Middelkoop, H.: Floodplain sedimentation: Quantities, patterns and processes, Earth Surf. Proc. Land., 20, 481-499, doi:10.1002/esp.3290200602, 1995.

Baborowski, M., Büttner, O., Morgenstern, P., Krüger, F., Lobe, I., Rupp, H., and Tümpling, W. V: Spatial and temporal variability of sediment deposition on artificial-lawn traps in a floodplain of the River Elbe, Environ. Poll., 148, 770-778, doi:10.1016/j.envpol.2007.01.032, 2007.

Büttner, O., Otte-Witte, K., Krüger, F., Meon, G., and Rode, M.: Numerical modelling of floodplain hydraulics and suspended sediment transport and deposition at the event scale in the middle river Elbe, Germany, Acta Hydroch. Hydrob., 34, 265-278, doi:10.1002/aheh.200500626, 2006.

Dung, N. V., Merz, B., Bárdossy, A., Thang, T. D., and Apel, H.: Multi-objective automatic calibration of hydrodynamic models utilizing inundation maps and gauge data, Hydrol. Earth Syst. Sci., 15, 1339-1354, doi:10.5194/hess-15-1339-2011, 2011.

Ericson, J., Vorosmarty, C., Dingman, S., Ward, L., and Meybeck, M.: Effective sea-level rise and deltas: Causes of change and human dimension implications, Global Planet. Change, 50, 63-82, doi:10.1016/j.gloplacha.2005.07.004, 2006.

Fu, K. and He, D.: Analysis and prediction of sediment trapping efficiencies of the reservoirs in the mainstream of the Lancang River, Chinese Sci. Bull., 52, 134-140, doi:10.1007/s11434-0077026-0, 2007.

Fu, K. D., He, D. M., and Lu, X. X.: Sedimentation in the Manwan reservoir in the Upper Mekong and its downstream impacts, Quaternary Int., 186, 91-99, doi:10.1016/j.quaint.2007.09.041, 2008.

Gupta, H., Kao, S.-J., and Dai, M.: The role of mega dams in reducing sediment fluxes: A case study of large Asian rivers, J. Hydrol., 464-465, 447-458, doi:10.1016/j.jhydrol.2012.07.038, 2012.

Hung, N. N., Delgado, J. M., Tri, V. K., Hung, L. M., Merz, B., Bárdossy, A., and Apel, H.: Floodplain hydrology of 
the Mekong Delta, Vietnam, Hydrol. Process., 26, 674-686, doi:10.1002/hyp.8183, 2012.

Hung, N. N., Delgado, J. M., Guentner, A., Merz, B., Bardossy, A., and Apel, H.: Sediment in the floodplains of the Mekong Delta, Vietnam Part I: Suspended sediment dynamics, Hydrol. Process., online first, doi:10.1002/hyp.9856, $2013 \mathrm{a}$.

Hung, N. N., Delgado, J. M., Guentner, A., Merz, B., Bardossy, A., and Apel, H.: Sediment in the floodplains of the Mekong Delta, Vietnam Part II: deposition and erosion, Hydrological Processes, online first, doi:10.1002/hyp.9855, 2013b.

Kummu, M. and Varis, O.: Sediment-related impacts due to upstream reservoir trapping, the Lower Mekong River, Geomorphology, 85, 275-293, doi:10.1016/j.geomorph.2006.03.024, 2007.

Kummu, M., Lu, X. X., Wang, J. J., and Varis, O.: Basinwide sediment trapping efficiency of emerging reservoirs along the Mekong, Geomorphology, 119, 181-197, doi:10.1016/j.geomorph.2010.03.018, 2010.

Liu, C., He, Y., Walling, E., and Wang, J.: Changes in the sediment load of the Lancang-Mekong River over the period 19652003, Science China Technological Sciences, 56, 843-852, doi:10.1007/s11431-013-5162-0, 2013.

Liu, J. P., Li, A. C., Xu, K. H., Velozzi, D. M., Yang, Z. S., Milliman, J. D., and DeMaster, D. J.: Sedimentary features of the Yangtze River-derived along-shelf clinoform deposit in the East China Sea, Cont. Shelf Res., 26, 2141-2156, doi:10.1016/j.csr.2006.07.013, 2006.

Liu, X. and He, D.: A new assessment method for comprehensive impact of hydropower development on runoff and sediment changes, J. Geogr. Sci., 22, 1034-1044, doi:10.1007/s11442012-0981-7, 2012.

Lu, X. X. and Siew, R. Y.: Water discharge and sediment flux changes over the past decades in the Lower Mekong River: possible impacts of the Chinese dams, Hydrol. Earth Syst. Sci., 10, 181-195, doi:10.5194/hess-10-181-2006, 2006.

MARD - Vietnamese Ministry of Agriculture \& Rural Development: Water resources planning of the Vietnamese Mekong Delta adaptation with climate change and sea level rise, Report, available at: http://www.vncold.vn/Web/Content.aspx? distid=2927 (last access: April 2013), 2012 (in Vietnamese).

Mendenhall, W., Beaver, R. J., and Beaver, B. M.: Introduction to Probability and Statistics, Brooks/Cole, Cengage Learning., 307-309, 2009.

Merz, B. and Thieken, A. H.: Separating natural and epistemic uncertainty in flood frequency analysis, J. Hydrol., 309, 114-132, doi:10.1016/j.jhydrol.2004.11.015, 2005.

Middelkoop, H.: Floodplain Sedimentation - Methods, Patterns, and Processes, A Review with exambles from the lower Rhine, the Netherlands, Encyclopedia of Hydrological Sciences, 84, 1242-1282, doi:10.1002/0470848944.hsa085, 2005.

Milliman, J. D. and Farnsworth, K. L.: River Discharge to the Coastal Ocean: A Global Synthesis, Cambridge University Press., 143-144, 2011.

MRC - Mekong River Commission: Multi-functionality of Paddy Fields over the Lower Mekong Basin, Technical Paper (26), available at: http://www.mrcmekong.org/assets/Publications/ technical/tech-No26-multi-functionality-of-paddy-field.pdf (last access: 7 April 2013), 2010.
MRC - Mekong River Commission: Flood Situation Report 2011, Technical Paper (36), available at: http://www.mrcmekong.org/assets/Publications/technical/ Tech-No36-Flood-Situation-Report2011.pdf (last access: 7 May 2013), 2011.

Navratil, O., Esteves, M., Legout, C., Gratiot, N., Nemery, J., Willmore, S., and Grangeon, T.: Global uncertainty analysis of suspended sediment monitoring using turbidimeter in a small mountainous river catchment, J. Hydrol., 398, 246-259, doi:10.1016/j.jhydrol.2010.12.025, 2011.

Pappenberger, F. and Beven, K. J.: Ignorance is bliss: Or seven reasons not to use uncertainty analysis, Water Resour. Res., 42, W05302, doi:10.1029/2005wr004820, 2006.

Salas, J. D. and Shin, H.-S.: Uncertainty analysis of reservoir sedimentation, J. Hydraul. Eng.-ASCE, 125, 339-350, 1999.

Shamsudin, S., Rashid, A., Darom, M., Mohamad, I. N., Rahman, A. A., Campus, I., and Lumpur, K.: Detention Pond Sediment Accumulation Prediction using Monte Carlo Simulation, Am. J. Environ. Sci., 8, 25-34, 2012.

Shenliang, C., Guoan, Z., and Shilun, Y.: Temporal and spatial changes of suspended sediment concentration and resuspension in the Yangtze River estuary, J. Geogr. Sci., 13, 498-506, 2003.

Steiger, J., Gurnell, A. M., Ergenzinger, P., Snelder, D., and Universita, F.: Sedimentation in the riparian zone of an incising river, Earth Surf. Proc. Land., 108, 91-108, 2001.

Steiger, J., Gurnell, A. M., and Goodson, J. M.: Quantifying and characterizing contemporary riparian sedimentation, River Res. Appl., 19, 335-352, doi:10.1002/rra.708, 2003.

Syvitski, J. and Higgins, S.: Going under: The world's sinking deltas, New Scientist, 216, 40-43, doi:10.1016/S02624079(12)63083-8, 2012.

Syvitski, J. P. M. and Saito, Y.: Morphodynamics of deltas under the influence of humans, Global Planet. Change, 57, 261-282, doi:10.1016/j.gloplacha.2006.12.001, 2007.

Syvitski, J. P. M., Kettner, A. J., Overeem, I., Hutton, E. W. H., Hannon, M. T., Brakenridge, G. R., Day, J., Vörösmarty, C., Saito, Y., Giosan, L., and Nicholls, R. J.: Sinking deltas due to human activities, Nat. Geosci., 2, 681-686, doi:10.1038/NGEO629, 2009.

Thuyen, L. X., Tran, H. N., Tuan, B. D., and Bay, N. T.: Transportation and deposition of fine sediment during flood season in Long Xuyen Quadrangle, Technical Report - MOST (Vietnamese), 170, 2000.

Ve, N. B.: Assessment of sustainability of 3 rice crops in the Vietnamese Mekong Delta, An Giang workshop 2009 (Vietnamese), 2009.

Walling, D. E.: The changing sediment load of the Mekong River, Ambio, 37, 150-157, 2008.

Wang, H., Saito, Y., Zhang, Y., Bi, N., Sun, X., and Yang, Z.: Recent changes of sediment flux to the western Pacific Ocean from major rivers in East and Southeast Asia, Earth-Sci. Rev., 108, 80-100, 2011.

Wolanski, E., Huan, N. N., Dao, L. T., Nhan, N. H., and Thuy, N. N.: Fine-sediment Dynamics in the Mekong River Estuary, Vietnam, Estuar. Coastal Shelf S., 43, 565-582, doi:10.1006/ecss.1996.0088, 1996.

Xue, Z., Liu, J. P., DeMaster, D., Van Nguyen, L., and Ta, T. K. O.: Late Holocene Evolution of the Mekong Subaqueous Delta, Southern Vietnam, Marine Geol., 269, 46-60, doi:10.1016/j.margeo.2009.12.005, 2010. 
Yang, S. L., Belkin, I. M., Belkina, A. I., Zhao, Q. Y., Zhu, J., and Ding, P. X.: Delta response to decline in sediment supply from the Yangtze River: evidence of the recent four decades and expectations for the next half-century, Estuarine Coast. Shelf S., 57, 689-699, doi:10.1016/S0272-7714(02)00409-2, 2003.
Yoshimura, C., Zhou, M., Kiem, A. S., Fukami, K., Prasantha, H. H. A., Ishidaira, H., and Takeuchi, K.: 2020s scenario analysis of nutrient load in the Mekong River Basin using a distributed hydrological model, Sci. Total Environ., 407, 5356-66, doi:10.1016/j.scitotenv.2009.06.026, 2009. 